\title{
BERNARD MANDEVILLE Y LAS PARADOJAS DE UN FABULADOR SATÍRICO
}

\author{
Manuel Salguero Salguero ${ }^{1}$
}

\section{Resumen}

El molesto espejo de la Fábula de las abejas ha llamado la atención de importantes autores y Bernard Mandeville, conocido sobre todo como el autor de esa fábula, adquirió merecida fama en la cultura europea de la ilustración. La actualidad de Mandeville parece indiscutible porque se aprecia en sus obras un discurso legitimador del libre mercado propio de una sociedad comercial abierta y próspera, en el que se produce la siguiente paradoja: el propio interés y los vicios privados proporcionan de forma espontánea el bienestar público. Defendía, como atributo de este modelo de sociedad burguesa, el lujo, la avaricia y el egoísmo en todas sus manifestaciones pero lo hacía, adoptando como recurso satírico, un concepto ascético de la virtud. Con este recurso irónico pretendía desenmascarar la hipocresía de la moralidad de su tiempo porque ahondando en esa idea de virtud siempre aparece alguna forma de egoísmo. Mandeville estaba convencido de que el verdadero impulso para la acción proviene de las pasiones que anidan en la naturaleza humana.

Palabras clave: fábula de las abejas, vicios privados, bienestar público, virtud ascética, sociedad comercial abierta, fabulador satírico, políticos sagaces, virtudes tranquilas, pasiones egoístas

\section{RASGOS DE LA PERSONALIDAD DE BERNARD MANDEVILLE $Y$ CARACTERIZACIÓN GENERAL DE SU PENSAMIENTO.}

Bernard Mandeville pertenecía a una familia en la que, a lo largo de siglo XVI, abundaron hombre eminentes como gobernadores, médicos y distinguidos oficiales. Su antecedente familiar más lejano fue Joannes Mandeville que vivió en Friesland (Leeurwarden) alrededor de 1580. ${ }^{2}$ Michael, el ascendiente más lejano de Bernard Mandeville, fue nombrado médico de la ciudad de Nijmegen en 1661, respondía a la imagen representativa de un humanista de la época, y en torno a 1617 ocupó un puesto político como concejal. Uno de sus hijos, Emmanuel (el abuelo de Bernard Mandeville) estudió derecho en Leiden y fue profesor de la Academia de la ciudad, continuando con la tradición familiar. Su hijo Michael, uno de los muchos hijos que tuvo y que es el padre de Bernard Mandeville, estudió derecho en Leiden en 1666, tuvo también éxito en los estudios de medicina y fue nombrado médico en Rotterdam, ostentando, además, el cargo de concejal y otros de carácter militar. Contrajo matrimonio con Judith Verhear y tuvieron 4 hijos, entre los que está Bernard Mandeville, que nació en

\footnotetext{
${ }^{1}$ Catedrático de Filosofía del Derecho de la Universidad de Granada. E-mail: salguero@ugr.es

${ }^{2}$ DEKKER, R, "Private vices, Public Virtues Revised: The Dutch Background of Bernard Mandeville", History of European Ideas, vol. 4, 1992, pp. 482 y ss.
} 
Dordrecht (Holanda) en 1670³ y siguió los pasos de su padre y de su abuelo. Entre 1685 y 1691 estudió filosofía y medicina en Leyden, obteniendo su doctorado en filosofía en 1689. ${ }^{4}$ Su primer escrito de 1685 lleva por título " De Medicina Oratio Scholastica" y en 1689 defendió su trabajo académico sobre "Disputatio philosophica de Brutorum Operationibus", relacionando los estudios cartesianos con estas investigaciones sobre los animales. Posteriormente escribió su "Disputatio Medica Inauguralis de Chylosi Vitiatu", por el que obtuvo el grado en medicina. Bernard Mandeville practicó la medicina y se especializó como su padre en los estudios de las enfermedades nerviosas y psicológicas, entonces también denominadas pasiones hipocondríacas e histéricas. ${ }^{5}$

En 1690 volvió a Rotterdam con sus padres y allí tuvo ocasión de vivir los denominados "disturbios de Costerman" que marcaron al joven Bernard. Estos disturbios ${ }^{6}$, que tuvieron su origen en el descontento de la población de Rotterdam y otras ciudades holandesas por la excesiva fiscalización impositiva llevada a cabo por los cobradores de impuestos, dieron lugar a un incidente en el que el alguacil de la ciudad exigió la pena de muerte a un respetable miembro de la milicia. Estos disturbios implicaron a Michael y a Bernard Mandeville por haber organizado una reacción crítica, expresada por escrito en forma satírica. Se editaron muchas copias del poema satírico conocido como "Sanctimonious Atheist" que aludía a la corrupción política y a las extorsiones que se estaban produciendo. Proliferaron los panfletos satíricos, el ambiente se enrareció y se hizo poco favorable para las expectativas de la familia Mandeville. Después de estos disturbios, Bernard Mandeville regresó a Leiden donde obtuvo el doctorado en medicina en 1691. Después viajó durante algunos años por Europa, especialmente a París y a Roma para alejarse de la justicia holandesa. Finalmente se estableció en Londres en torno a 1694, donde contrajo matrimonio en febrero de 1699 y tuvo un hijo y una hija . ${ }^{7}$ Decidió quedarse en Londres hasta su muerte en Hackney en 1733, a la edad de 63 años. ${ }^{8}$

Bernard Mandeville, ya bien instalado en Londres, trabó amistad con Sir Hans Sloane, uno de los médicos más célebres de su tiempo, y con el rico y poderoso Conde de Macclesfield que llegó a ser Gran Canciller de Inglaterra en 1718 y que confió al autor de la Fábula de las abejas la curación de una enfermedad que padecía su hijo. Mandeville, que había publicado en 1711 su obra "A Treatise of the Hypochondriacck and Hystewrick Passions", gozaba de una gran reputación como especialista en enfermedades nerviosas como subraya G. Clark en su ensayo "B. Mandeville, MD and Eigteenth-Century Ethic"'.

Mandeville llegó a ser uno de los autores más leídos y célebres de su tiempo. Sobre su personalidad

\footnotetext{
${ }^{3}$ CARRIVE, P., Bernard Mandeville. Passions, Vices, Virtues, París, Libraire Philosophique, 1980, pp. 10 y ss.

${ }^{4}$ RÍOS ESPINOSA, Ma C., Fundamentación ética del mercantilismo. Bernard Mandeville: la paradoja del vicio en la sociedad, Publicackiones Cruz O., Máxico, 2002, p. 43.

${ }^{5}$ CARRIVE, Paulette, op. cit., p. 10.

${ }^{6}$ RÍOS ESPINOSA, Ma C., Fundamentación ética del mercantilismo, op. cit., pp. 43-50.

${ }^{7}$ CARRIVE, P., op. cit., p. 11.

${ }^{8}$ Para los datos biográficos: CARRIVE, P., Bernard Mandeville. Passions, Vices, Virtues, op. cit., pp. 9-23.

${ }^{9}$ Ibid,. p. 15.
} 
circularon rumores, insidias y maledicencias que tenían escaso fundamento. En este contexto hay que incluir la imagen del médico librepensador que aterraba a los ministros del culto, hombre de perniciosos principios, de sensualidad grosera y de costumbres disolutas. El autor de La fábula de las abejas, obra por la que era, sobre todo, conocido, ${ }^{10}$ tenía fama acreditada de ser el más gracioso y entretenido contertulio. ${ }^{11}$

Uno de los elementos dominantes de la obra de Mandeville es el presupuesto de que las exigencias que brotan de las pasiones y de las emociones son el verdadero motor de la conducta humana, por más que el intelecto esté siempre dispuesto a descubrir razones que justifiquen esas exigencias. Este presupuesto epistemológico y esta psicología de las pasiones estaban plenamente en vigor en la época de Mandeville, y reflejaban una desconfianza en la razón como instrumento para alcanzar la verdad. Pero el escepticismo que proclamaba Mandeville era más de carácter psicológico que lógico porque lo que quería reafirmar -como se desprende de su Investigación sobre el origen de la virtud moral- ${ }^{12}$ era que todos los seres humanos están regidos completamente por sus pasiones, aunque traten de ocultarlo o camuflarlo con bellas palabras, y que son las pasiones las que incitan a la acción. Lo novedoso de Mandeville no es la originalidad, sino la exposición brillante, incisiva e irónica de una psicología de las pasiones que era común en el pensamiento francés desde Montaigne, y era compartida por autores como Spinoza, La Rochefocauld, Pascal, Fontenelle, Bayle, Daniel Dyke.. La idea de que el hombre no está determinado por los registros de su facultad discursiva, sino por los impulsos de la pasión y del corazón era ampliamente compartida por todos estos autores. Asimismo, todos ellos -y también Mandeville- admitían que el corazón interrumpe, cuando le conviene, las reflexiones del espíritu y se pone del lado de la pasión, olvidando la exigencia racional de dominio de los deseos, porque del deber sólo tiene percepciones frías, mientras que se lanza con ardor a cuanto favorece sus inclinaciones. Para todos estos autores, en especial Montaigne y La Rochefoucauld ${ }^{13}$ a los que sigue

\footnotetext{
${ }^{10}$ Con respecto a sus obras pueden destacarse las siguientes: Typhon: or the Wars between the Gods and Giant: a Bourlesque Poem in Imitation of the Comical Monsieur Scarron (1704); The Grumbling Hive: or Knaves Turn'd Honets (1705); The Virgin Unmask'd: or Female Dialogues betwixt an Elderly Maiden Lady and her Niece (1709); A Treatise of the Hypocdriaack and Hysterick Passions (1711); The Fable of the Bees: or Private Vices, Publick Benefits (1714); Free Thoughts on Religion, the Church, and National Happiness (1720); The Fable of the Bees (2a edición), Remarks (20 Observaciones), An Essay on Charity and Charity-Schoolsy A Search into the Nature of Society (1723); A Modest Defense of Publick Stews (1724); The Fable of Bees, Part II (1729); An Inquiry into the Origin of Honour, and the Usefulness of Christianity in War (1732). Cfr. CARRIVE, P., Bernard Mandeville. Passions, Vices, Vitues, op. cit.. pp. 9-23. Para la historia del texto y las ediciones, véase el estudio introductorio de F.B. Kaye pp. XXXI- XXIV. En lo que hace referencia a los antecedentes de la obra en autores como Erasmo, Hobbes, La Rochefoucauld, Pascal, Spinoza, Locke..., véase Kaye, ibid. pp. XLIX-LVIII. Cfr. listado de obras de Mandeville: F.B. KAYE, op. cit., pp. XXXI-XXII.

${ }^{11}$ KAYE, F.B., "Introducción”, en MANDEVILLE, B., La fábula de las abejas o los vicios privados hacen la prosperidad pública, (1ª edición en inglés de 1729, edición facsímil 1924 de Clarendon Press, 1a edición en español 1982, 1ª reimpresión 1997), traducción de Ferrater Mora, comentario crítico, histórico y comparativo de F.B. Kaye, México, F.C.E., 1a reimpresión 1997, pp. XIII-XXIII. Cuando citemos en lo sucesivo La fábula de las abejas lo haremos por esta 1a reimpresión de 1997 con la traducción de Ferrater Mora.

${ }^{12}$ MANDEVILLE, B, La fábula de las abejas, op. cit., pp. 23-32.

${ }^{13}$ Cfr. PASCAL, LA ROCHEFOUCAULD, LA BRUYĖRE, VAUVENARGES, CHAMPORT, JOUBERT, Moralistas franceses. Máximas, pensamientos y caracteres, introducción de Alicia Illera, ed. de José Antonio Millán Alba, trad. de Salustiano Masó y José
} 
Mandeville, la mayoría de las más bellas acciones del alma (como la piedad o la benevolencia) proceden del impulso de las pasiones, y es siempre el corazón el que hace hablar al espíritu o este es siempre la víctima del corazón.

Mandeville estaba también familiarizado ${ }^{14}$ con la psicología sensualista de Hobbes o de Locke y con el determinismo psicológico de Gassendi ${ }^{15}$ que concibe al hombre como una máquina sintiente donde la razón se torna en espectador de las reacciones físicas. ${ }^{16}$ Mandeville se sentía próximo a estas posiciones, por su práctica de la medicina, como ya se ha subrayado, y ponía en relación la constitución mental y moral derivada de los humores o fluidos corporales, de modo que las virtudes acaban siendo el resultado del temperamento. ${ }^{17}$

Nos importa destacar, además, la tesis tan genuina de Mandeville de que el hombre es del todo egoísta y que el altruismo no es, en realidad, otra cosa que una forma disfrazada de egoísmo. Cuando se escudriña hasta el fondo la magnanimidad o la piedad allí se encuentra el egoísmo. Esta tesis del egoísmo ya había sido destacada por Hobbes, y Mandeville continúa por esta senda del análisis psicológico del egoísmo humano que en su tiempo tenía una acreditada presencia en autores como La Rochefoucauld, Pascal, ${ }^{18}$ Jaques Esprit, Fontenelle, Bossuet, Robert Waring o John Norris. ${ }^{19}$ El interés es siempre el móvil de las acciones de modo que la amistad perfecta y el desinterés no son más que una quimera inalcanzable. La virtud no es otra cosa que una forma de amarse a sí mismo. Así, por ejemplo, la constancia se reduce a una vana ostentación de la fuerza del alma y a un deseo de sobreponerse a la mala suerte, y la magnanimidad consiste en un deseo de aparentar sentimientos elevados. En definitiva, el amor propio es el resorte principal de toda nuestra conducta y la virtud es tan solo un egoísmo edulcorado con suaves epítetos.

Otro aspecto importante es la defensa que hace Mandeville del lujo frente a la frugalidad que, en realidad, no es virtud ni tiene que ver con la moralidad, sino que es el resultado inevitable de ciertas condiciones económicas. Lejos de pensar que el lujo y la prodigalidad constituyen un peligro o un inconveniente para la economía, Mandeville se esforzaba por justificar que son inseparables de los grandes Estados y son la condición

\footnotetext{
Antonio Millán Alba, Biblioteca de Literatura Universal, Córdoba, Almuzarra, 2008. Véase, en especial, Máximas de La Rochefoucauld, ibid., pp. 393-463.

${ }^{14}$ Véase, en especial, el "Cuarto diálogo" en La fábula de las abejas II Parte, en MANDEVILLE, B., La fábula de las abejas, F.C.E., op. cit., pp. 467-468.

${ }^{15}$ Gassendi, en su réplica a Descartes dice: “...at quedadmodum, licet homo sit praestantissimum animalium, non eximitur tamen ex animalium numero”, en DESCARTES, R., Meditationes de prima philosophia, objectiones quintae, II, 7. Mandeville cita a Gasssendi en el "Prefacio" en La fábula de las abejas II parte, ibid., p. 356.

${ }^{16}$ Resuslta, en este aspecto, significativa la obra de HOLBACH, Sistema de la naturaleza humana, trad. De Nerida Bacín y otros, Editorial Laetoli, Pamplona, 2008.

${ }^{17}$ Así, podemos leer en "Observaciones" (La fábula de las abejas, II Parte, op. cit. p. 138) que "la resolución depende del tono de dichos humores, $[y]$ es evidente también, por los efectos de los licores fuertes, cuyas ardientes partículas, agolpándose en el cerebro, fortifican el espíritu; los resultados son semejantes a los de la ira, que ya he dicho antes que era una ebullición de los humores".

${ }^{18}$ Cfr. PASCAL, LA ROCHEFOUCAULD, LA BRUYÈRE, VAUVENARGES, CHAMPORT, JOUBERT, Moralistas franceses. Máximas, pensamientos y caracteres, op. cit.

${ }^{19}$ Véase nota no 154: KAYE, F.B., "Introducción”, en MANDEVILLE, B., La fábula de las abejas, op. cit., pp. 289-290.
} 
indispensable de que éstos se hagan prósperos. El lujo, la ostentación, el derroche y la codicia acaban siendo los mejores aliados de una sociedad poderosa porque "todas esas plagas y monstruos" podrán "lograr que se realicen todos los trabajos que el ingenio de los hombres es capaz de inventar para procurar medios de vida honrados a las grandes multitudes de trabajadores pobres que se requieren para hacer una gran sociedad". ${ }^{20}$ Es necedad pretender que sin el lujo o la codicia puedan existir naciones grandes y ricas que sean, al mismo tiempo, poderosas y cultas. Por eso afirma al final de las Observaciones que "jamás hubo ni habrá frugalidad nacional sin pobreza nacional". ${ }^{21}$ Por tanto, el lujo y el consumo de cosas superfluas lejos de ser un vicio peligroso resulta ser un ingrediente necesario del engrandecimiento de los Estados, y se trata de una constatación empírica que se ocupa de justificar Mandeville entrando en consideraciones económicas y comerciales de los más variados registros. ${ }^{22}$

Suele caracterizarse, en general, a Mandeville como un filósofo que hace depender la prosperidad económica de la promoción de los vicios privados. Mandeville planteaba la paradoja de que los vicios privados tales como la avaricia, el egoísmo, el orgullo o la envidia se convierten en beneficios públicos y en prosperidad económica en una sociedad comercial. La paradoja, ${ }^{23}$ consistente en que en la creación de algo bueno (la prosperidad económica) a partir de algo malo (los vicios privados), plantea la cuestión acerca de si en una sociedad comercial un individuo puede ser un buen ciudadano. La respuesta de Mandeville es negativa porque para ser un buen ciudadano en una sociedad comercial hay que actuar motivado por la codicia y los demás vicios que son contrarios a lo que es exigible de quien pretenda ser un buen ciudadano.

Lo que se ha convertido en objeto de debate no es la conexión que se establece entre prosperidad económica y vicios privados, sino si Mandeville propugnaba un sistema tal como ese. En este sentido, se han formulado dos posiciones: la tradicional (ya iniciada por los coetáneos que consideran que Mandeville propugna un sistema en el que vicio privado se transforma en beneficio público), y la de aquellos que lo consideran como una autor satírico que describe una sociedad en la que se produce esa paradoja, pero que advierte a los lectores de que en una sociedad comercial opulenta la corrupción, la inmoralidad y toda clase de vicios habrán de reinar indefectiblemente.

Desde la primera publicación de la Fabula de las abejas, Mandeville fue acusado de propugnar un sistema social que se sustentaba en el vicio, lo que suscitó muchas críticas de sus contemporáneos. ${ }^{24}$ Además de aquellos

\footnotetext{
20 “Investigación sobre la naturaleza de la sociedad”, en La fábula de las abejas, op. cit., p.238.

${ }^{21}$ La fábula de las abejas, op. cit., p. 164.

22 “Investigación sobre la naturaleza de la sociedad”, en La fábula de las abejas, op. cit., pp. 238-249.

${ }^{23}$ Así expresa el autor esta paradoja: “...Los que pueden ensanchar su visión...podrán ver en cien lugares cómo el bien emerge y pulula del mal, con tanta naturalidad como los polluelos de los huevos” (MANDEVILLE, B., Reivindicación del libro, en La fábula de la abejas, op. cit., p. 261).

${ }^{24}$ John Dennis, William Law, Hume, Berkeley, Hutcheson, Godwin, Holberg, John Brown, Fielding, Diderot, Holbach, Rousseau, Malthus, James Mill, Kant, Adam Smith, John Wesley, Herder, Montesquieu, Bentham... El libro causó una verdadera consternación, que abarcó desde la indignación del obispo Berkeley al horrorizado asombro de John Wesley, quien decía que ni
} 
críticos coetáneos, otros autores recientes han destacado -aunque con distintos matices- ${ }^{25}$ esta misma idea de que Mandeville propugnaba una teoría social en la que los vicios proporcionan beneficios públicos, mientras que las virtudes cristianas contrarias a esos vicios no favorecen el bien común de una sociedad comercial. M. Goldsmith, ${ }^{26}$ representa una posición complementaria entre la tradicional y la que considera a Mandeville como un autor satírico. Para Mandeville el vicio es esencial para el florecimiento de la sociedad en un doble sentido. Por un lado, el vicio entendido como defecto, privación o necesidad aporta la idea de que es necesario para la supervivencia humana. Por otro, el vicio, en su sentido moral, estimula el desarrollo de una sociedad comercial extensa y próspera. Goldsmith sugiere que Mandeville acepta la paradoja de la fábula como un prerrequisito del éxito de la sociedad comercial, en cuanto que el vicio (lujo, corrupción...) se vinculan con la riqueza, el poder y la prosperidad, y la virtud con la sencillez y las condiciones elementales de la existencia. ${ }^{27}$ Sin embargo, Mandeville, no aprobaba o alentaba el vicio, sino que con frecuencia lo condenaba. Frente a la severa crítica que le hizo el obispo y filósofo Berkeley, la Fábula de la abejas "no prescribe lo que describe"28 como algo que es característico de una sociedad opulenta. En efecto, hay muchos lugares en donde Mandeville se defiende de sus críticos diciendo que prefiere una sociedad en la que los ciudadanos sean virtuosos y honestos a una sociedad corrupta y viciosa. Pero se defiende, sobre todo, en la Reivindicación del libro ${ }^{29}$ donde se expresa del siguiente modo:

Es un libro de moralidad severa y exaltada, que contiene estrictas pruebas de virtud y es una infalible piedra de toque para distinguir lo real de lo deformado, demostrando que son culpables muchas acciones que el mundo se toman por buenas. Describe la naturaleza y los síntomas de las pasiones humanas, determina su potencia y sus disfraces, y descubre al amor propio en sus más recónditos escondrijos. (...) Cuando digo que las sociedades no pueden elevarse a la riqueza ni alcanzar la cumbre de la gloria terrenal sin vicios, no creo que con esto postule que los hombres sean viciosos. (...) Investigar las causas reales de las cosas no importa [conlleva] ningún mal designio ni tiende a dañar en manera alguna. Un hombre puede escribir sobre venenos, siendo un

siquiera Voltaire hubiera sido capaz de decir tanta iniquidad. "EEn Francia, sin vacilar, se ordenó la quema de la Fábula por el verdugo!". Decía Diderot que en Francia la Fábula de las abejas era allí tema familiar de conversación. En Alemania, cuando Kant en 1788 clasificó en seis los sistemas éticos, escogió el nombre de Mandeville para identificar uno de ellos. Y en América, el autor de la primera comedia norteamericana (Royall Tyler) alude a Mandeville como si sus teorías fueran tan bien conocidas del auditorio. Cfr. KAYE, F.B., Introducción, op. cit, p. LXVI.

${ }^{25}$ SCOTT, Kyle, "Mandeville's Paradox as Satire: The Moral Consequences of Being a Good Citizen in a Commercial Society", Politics \& Policy, n² 2, vol. 37, Abril, 2009, pp. 372-376.

${ }^{26}$ GOLDSMITH, M. M., Private Vices Public Benefits: Bernard Mandeville's Social and Political Thought, (Revised Edition), Christchurch, New Zealand, Cybereditions Corporation, 2001. Ubicación en la red: http://site.ebray.com/lib/univgranada/Doc?id=5005520\&ppg=1

${ }^{27}$ Ibid.,p. 39 y 55.

${ }^{28}$ Ibid, p. 59.

${ }^{29}$ El subtitulo es el siguiente: De las difamaciones contenidas en una denuncia del Gran Jurado de Middlesex y en una carta improcedente a Lord C., en MANDEVILLE, B., La fábula de las abejas, op. cit., pp. 249-267. 
excelente médico. ${ }^{30}$

Otros estudiosos de Mandeville destacan la dimensión satírica e irónica de los escritos de este autor y su condición de fabulador. Según esta perspectiva, Mandeville era, ante todo, un crítico acervo de la sociedad de su tiempo a la que describe tal cual cree que es, libre de disfraces y de hipocresías. Penetra en la sociedad de su tiempo dando cuenta de que el orgullo, la vanidad, la envidia, la codicia y demás vicios -todos ellos contrarios a las virtudes cardinales- pueden resultar beneficiosos desde el punto de vista económico. Pero insiste en que esos vicios son plagas y monstruos y que es preferible la virtud. Como subraya Thomas Horne, uno de los autores que ve a Mandeville como un autor satírico, el problema moral de la sociedad comercial consiste en que dicha sociedad florece más cuando se hace presente el egoísmo y se repliega cuando hace acto de presencia el altruismo. Señala este autor que Mandeville no era defensor de una sociedad comercial en la que se tenga que sacrificar la virtud individual en favor del vicio, sino que se limitaba con fina ironía satírica a advertir lo que sucede en la sociedad que aspira al éxito, a la acumulación de la riqueza y la prosperidad propias de una sociedad comercial opulenta. ${ }^{31}$ Mandeville construyó un tipo de persona dominada por el egoísmo y el propio interés que puede ser manipulado por la habilidad de los políticos. Esto significa que el vicio privado no promueve por un mecanismo natural el beneficio público, sino que "los vicios privados, manejados diestramente por un hábil político, pueden trocarse en beneficios públicos". ${ }^{32}$

Esta dimensión satírica e irónica ${ }^{33}$ se complementa con su vinculación a la tradición fabular como han destacados varios autores. ${ }^{34}$ Como fabulador satírico, Mandeville intentaba mostrar la incompatibilidad existente entre prosperidad y virtud en las sociedades desarrolladas pues en éstas la virtud se sustituye por el orgullo y la codicia. La Fábula de las abejas intenta, como es propio del apólogo, educar y extraer una moraleja que trascienda a su propio tiempo: no puede haber honradez en una sociedad opulenta. Mediante el recurso a la fábula satiriza el vicio y la hipocresía, al comprobar que los actos humanos, aunque aparentemente sean desinteresados, en realidad son una falsa pretensión y un disfraz de las diferentes manifestaciones del vicio.

\footnotetext{
${ }^{30}$ Reivindicación del libro, op. cit., pp. 262 y 264. Hay otros lugares donde Mandeville refleja este tipo de argumentación: Investigación sobre el origen de la virtud moraly en Observaciones (MANDEVILLE, B., La fábula de las abejas, op. cit., pp. 23-33 y 33-165). También, en A Lewtter to Dion, (Londres, 1732). Cfr. SCOTT, K., op. cit, pp. 382-387.

${ }^{31}$ HORNE, TH., "Evy and Commercial Society: Mandeville and Smith on 'Prive Vices, Public Benefits", Political Theory, 9 (4), 1981, pp. 551-569.

${ }^{32}$ MANDEVILLE, B., Investigación sobre la naturaleza de la sociedad, op. cit,, p. 248. Un extenso estudio sobre esta idea del político hábil ("The skilfull Politicians") se encuentra en GOLDSMITH, M., op. cit., pp. 50-76.

${ }_{33}^{33}$ Un ejemplo muy explícito de este carácter satírico e irónico lo podemos ver en Ensayo sobre la caridad y las Escuelas de caridad. En este ensayo Mandeville dice que si se desea mantener una nación rica, próspera y feliz es preciso asegurarse una multitud de pobres laboriosos e ignorantes. Por eso, "la felicidad de todo el Estado o reino exige que los conocimientos de la clase pobre trabajadora se limiten a la esfera de sus ocupaciones y que nunca se extiendan más allá de lo que se relacione con su profesión”. En realidad, Mandeville lo que hacía era condenar una sociedad que se comporta de este modo y la intencionalidad satírica es evidente. MANDEVILLE, B., Ensayo sobre la caridad y las Escuelas de caridad, en La fábula de las abejas, op. cit, pp. 188 y ss.

${ }^{34}$ Entre otros, DANIEL, ST., Mith and Modern Philosophy, Philadelphia, Temple University Press, 1990; EDWARDS, TH., “Mandeville's Moral Prose", ELH,31 (2), 1964, pp. 195-212.
} 
Mandeville concibe la naturaleza humana de un modo fundamentalmente similar al de Hobbes en su Leviatán y De Cive. ${ }^{35}$ Los seres humanos sólo persiguen su propio placer y egoísmo sin considerar las consecuencias para los demás, por lo que sus deseos conducen necesariamente al conflicto. Mandeville comparte con San Agustín y con Hobbes el carácter de la naturaleza caída del hombre que busca cómo satisfacer incesantemente sus apetitos y pasiones, lo que conduce a la autopreservación del individuo y de la especie. Para explicar el origen de la sociedad, Mandeville afirma que no hay una sociabilidad natural o un amor innato hacia los demás, ${ }^{36}$ sino determinadas características físicas y psicológicas que lo capacitan para aprender a vivir en sociedad. Características tales como el incremento constante de sus necesidades, el orgullo, amor a sí mismo, vanidad, codicia, envidia o la búsqueda de la aprobación de los demás son las que hacen a los hombres aptos para la sociedad, sin necesidad de acudir a la ficción del contrato social. Así, dice Mandeville:

"Me congratulo de haber demostrado que ni las cualidades amistosas ni los afectos simpáticos que son naturales en el hombre, ni las virtudes reales que sea capaz de adquirir por la razón (...) son los cimientos de la sociedad; sino que, por el contrario, lo que llamamos mal e este mundo, sea moral o natural, es el gran principio que hace de nosotros seres sociables". ${ }^{37}$

En definitiva, el origen de la moralidad y de la sociedad se remite a una artimaña de los políticos hábiles ("skilfull politicians"). Buscando en los escritos de Mandeville, ${ }^{38}$ pueden descubrirse las instancias o instituciones que llevan a cabo esos políticos hábiles. El trabajo de estos sagaces políticos consiste en hacer que cada cosa esté en el lugar apropiado, en extraer lo bueno a partir de lo malo o vicioso y en distribuir empleos de forma acorde con los talentos. Así, surge la institución de los jueces, de los teólogos, filósofos o moralistas, de los legisladores, banqueros o terratenientes. ${ }^{39}$ Estas instituciones llevan a cabo un complejo proceso de socialización -mediante incentivos y gratificaciones- por quienes, en realidad, se mueven por intereses egoístas y para satisfacer sus propias pasiones. La virtud es, por tanto, una hipocresía ${ }^{40}$ o cualquier máscara del impulso egoísta elaborada por los legisladores que se muestran como héroes, por los moralistas y por los políticos sagaces. La sociabilidad no es, en definitiva, un deseo natural de asociarse con los otros seres humanos ni hay un amor innato por los de la especie. Los hombres están preparados para la sociedad como las uvas lo están para el vino. Los seres humanos tiene unas características que les permiten entrar en una red de relaciones sociales y se hacen sociables viviendo juntos en

\footnotetext{
${ }^{35}$ Sobre todo en Investigación sobre la naturaleza de la sociedad (op. cit.) y en The Famale Tatler, ed. M. Goldmith, Bristol, 1999. Cff. GOLDSMITH, M., op. cit., pp. 50 y ss.

${ }^{36}$ Así se expresa, al respecto, Mandeville: "Porque si por sociedad sólo entendiéramos una cantidad de gente que, sin ley ni gobierno, se mantiene unida a causa de un natural afecto hacia su especie o por amor a la compañía, como un hato de vacas o una majada de ovejas, no existiría en el mundo criatura menos apta para la vida en sociedad”. (MANDEVILLE, B., Investigación sobre la naturaleza de la sociedad, op. cit., p. 232).

${ }^{37}$ Ibid., p. 248.

${ }^{38}$ Cfr. GOLDSMITH, M., op. cit., pp. 55 y ss.

${ }^{39}$ The Famale Tatler, ed. M. Goldmith, Bristol, 1999. Cfr. GOLDSMITH, M., Private vices,...pp. 55 y ss.
} vol.10, n. 02, Rio de Janeiro, 2017.pp. 867-897 
sociedad.

\section{LA PARADOJA Y LA VERDADERA TESIS DE LA FÁBULA DE LAS ABEJAS.}

Cuando Mandeville publicó en 1714 la Fábula de las abejas catalizaba las contradicciones de su época que estaban alimentadas por la contraposición entre la actitud científica del racionalismo deísta y las exigencias de un rigorismo o ascetismo moral cristiano proyectado hacia un mundo ultraterreno. La religión, en la creencia cristiana, no sólo está en contradicción con la razón, sino que, según Mandeville, se halla en conflicto con la naturaleza humana porque ordena someter y dominar los deseos naturales del hombre porque éstos brotan de su naturaleza corrompida por el pecado original. Pero la humanidad nunca se ajustará, según Mandeville, a esa disciplina cristiana y se mostraba convencido de que no podrá impedirse que los seres humanos se rijan por sus inclinaciones constitutivas, pasiones o deseos. Frente al optimismo que lleva a pensar que los individuos pueden transformar las malas pasiones de la naturaleza en virtudes personales, Mandeville compartía con Pierre Bayle ${ }^{41}$ un escepticismo que conducía a la desconfianza en la posibilidad del esfuerzo humano para alcanzar la verdad que acabará en la imposibilidad de compatibilizar religión y razón.

En La fábula de las abejas Mandevile supo poner ante los ojos de sus contemporáneos la persistente contradicción -que se remontaba al mundo clásico y que fue asumida por la mentalidad cristiana- entre la condena del lujo como un mal moral y la búsqueda constante de la riqueza asociada al lujo y al consumo de cosas superfluas. Mientras que en el plano ideal se condenaba el lujo y se pensaba que la riqueza podía adquirirse sin él, en la práctica el lujo y el consumo de cosas superfluas se asocian inseparablemente con los Estados fuertes y económicamente florecientes. Mandeville puso en colisión ese dualismo y desafió a sus contemporáneos al hacer evidente la paradoja moral de que los vicios privados se tornan en beneficios públicos. ${ }^{42}$

\footnotetext{
${ }^{40}$ Así se expresa Mandeville: "En todas las sociedades civiles se enseña insensiblemente a los hombres a ser hipócritas desde la cuna y nadie se atreve a confesar lo que gana con las calamidades públicas". MANDEVILLE, B., Investigación sobre la naturaleza de la sociedad, op. cit., p. 233.

${ }^{41}$ BAYLE, P., Dictionaire des lettres et critique, 2 vols. Rotterdam, 1697; Oeuvres Diverses contenant tout ce que cet Auteur a publié sur des matières de Theologie, de Philosophie, de Critique, d'Histoire\& Littérature excepté son Dictionaire Historique et Critique, 4 vols., The Hague, 1727-1731. Mandeville solía citar las obras de Bayle en las traducciones inglesas de la época. Este es el caso, sobre todo, de Pensées diverses à l'occasion de la comete, que hace las referencias de las Miscellaneous Reflections, Occassione'd by the Comet, (1708).

${ }^{42}$ Como ya se ha indicado, Mandeville quedó preanunciado en autores como Montaigne, Bayle, Pierre Nicole, Fontenelle o La Rochefoucauld. Así, Montaigne decía que "en toda comunidad existen oficios necesarios, no solamente abyectos, sino incluso viciosos: los vicios se acoplan y se utilizan para la costura de nuestra ligazón, como los venenos para la conservación de nuestra salud" (Essais, III ). Pierre Nicole insiste en llamar viciosas a las pasiones, a pesar de su utilidad práctica (Essais de morale). Fontenelle se cuestiona si no sería peligroso intentar curar los defectos cuando resulta que las buenas cualidades de un hombre depende de otras malas (Dialogues des mortes). La Rochefoucauld decía que las pasiones pueden convertirse en ingredientes de una verdadera virtud, donde queda implícita la paradoja -también perceptible en otros autores- de que los vicios pueden ser beneficiosos. Sin embargo, en estas anticipaciones existe la convicción de que el individuo puede transformar las malas pasiones naturales en virtudes personales. Sin embargo, este optimismo no es compartido por Mandeville.
} 
La fábula se inicia con el relato alegórico de la colmena en versos rimados, ${ }^{43}$ en el que se pueden apreciar, tres momentos principales. En el primero se describe cómo el egoísmo, el lujo, la lujuria, la comodidad, la vanidad, la avaricia, el orgullo, la envidia, la pereza y las diferentes formas de la deshonestidad reinan en todos los espacios y oficios de la colmena (comerciantes, médicos, abogados, ministros del culto, estadistas, soldados...). ${ }^{44}$ El resultado de estos vicios constituía la prosperidad pública, de modo que la situación de la colmena no podía ser mejor ni su escenario más halagüeño:

$$
\begin{aligned}
& \text { "cada parte estaba llena de vicios } \\
& \text { pero todo el conjunto era un paraíso. } \\
& \text { Así el vicio nutría al ingenio } \\
& \text { el cual, unido al tiempo y a la industria, } \\
& \text { traía consigo las conveniencias de la vida. } \\
& \text { Los verdaderos placeres, comodidad, holgura } \\
& \text { en tal medida, que los mismos pobres } \\
& \text { vivían mejor que antes los ricos, } \\
& \text { y nada más podría añadirse". }
\end{aligned}
$$

El segundo momento se aprecia cuando las abejas de la colmena no quieren que sus vicios se mezclen con su prosperidad. Los más hipócritas y tramposos eran quienes querían hacer ostentación del estado moral de su país y pedían a los dioses honestidad:

$$
\begin{aligned}
& \text { "cual criaturas perdidas sin remedio, } \\
& \text { maldecían a sus políticos, ejércitos y flotas, } \\
& \text { al grito de "imueran los bribones!" } \\
& \text { y aunque sabedores de sus propios timos, } \\
& \text { despiadadamente no los toleraban en los demás. }{ }^{46}
\end{aligned}
$$

Esta petición de honestidad la hicieron llegar a Júpiter quien lleno de indignación por el estado de inmoralidad, otorga a la colmena que se cumpla su deseo de honestidad y virtud:

"Pero Júpiter movido de indignación, al fin airado prometió liberar por completo

\footnotetext{
${ }^{43} \mathrm{La}$ completa elaboración de la obra duró unos 24 años. El germen de la obra fue un pequeño libro de de unas 26 páginas, y que se vendía a seis penique, publicado anónimamente el dos de abril de 1705, y llevaba por título "The grambling Hive; or Knaves turne'd Honest" (El panal rumoroso o la redención de los bribones). El opúsculo tuvo éxito y se volvió a imprimir en una edición pirata que se voceaba por las calles a medio penique. En 1714 reapareció como parte de un libro anónimo titulado "The Fable of the bees: or Private Vices, Publick Benefits." Al poema original seguía un comentario en prosa (An Enquiry into the Origin of Moral Virtue) y veinte Observaciones diferentes sobre el poema. En 1723 se publicó una segunda edición con un mayor número de Observaciones y con dos ensayos más: An Essay on Charity and Charity-Schoolsy A search into the Nature of Society. En 1724 apareció la tercera edición y posteriormente aparecieron tres más con algunas variaciones. Mientras iban apareciendo estas ediciones Mandeville escribía una segunda parte de la Fábula de las abejas, compuesta por un prefacio y seis diálogos en los que ampliaba y defendía sus doctrinas. Esta segunda parte se publicó en 1729 con el título: The Fable of the Bees, Part II. By the Autor of the First. Hubo ediciones de esta segunda parte en 1730 y 1733. Después se publicaron conjuntamente las dos partes, primero en dos volúmenes $(1733,1755,1772)$. En 1795 aparecieron ambas partes en un solo volumen. Para un estudio más detallado de la historia del texto de esta obra, véase "Introducción " de F.B. Kaye MANDEVILLE, B., La fábula de las abejas o los vicios privados hacen la prosperidad pública, traducción de Ferrater Mora, comentario crítico, histórico y comparativo de, México, F.C., 1a reimpresión 1997, pp. XXII-XXIV.

${ }^{44}$ El poema se encuentra entre las páginas 11-21 de la indicada obra traducida por Ferrater Mora.

${ }^{45}$ Ibid, pp. 15 y 16

${ }^{46} \mathrm{Ibid}$.
} 
del fraude al aullante panal; y asílo hizo" 47

Después vienen las penosas consecuencias de introducir la honestidad y la moralidad en la colmena:

¡Cuán grande y súbito ha sido el cambio!

Los tribunales quedaron ya aquel día en silencio,

porque ya muy a gusto pagaban los deudores". 48

"Todos los ineptos, o quienes sabían

que sus servicios no eran indispensables, se marcharon.

No echaban a los hambrientos de su puerta,

ni pellizcaban del jornal de los pobres". 49

"El derroche se evitaba tanto como el fraude

No había ya ejércitos en el extranjero.

¡Contemplad ahora todo el panal, y ved

cómo concuerdan honradez y comercio! ${ }^{50}$

"Tan pocas abejas quedaron en el vasto panal,

que sólo podían mantener la centésima parte. ${ }^{S I}$

Al propio descanso consideraban vicio

Y para evitar extravagancias

hacia un tronco hueco emigraron (...),

bendecidas de contento y honradez". 52

El tercer momento es el que se incluye en la instructiva moraleja final:

Dejad, pues, de quejaros: sólo los tontos se esfuerzan

por hacer de un gran panal un panal honrado(...)

Fraude, lujo y orgullo deben vivir

mientras disfrutemos de los beneficios:

el hambre es, sin duda, una plaga terrible,

pero sin ella, ¿Quién medra o se alimenta?

La virtud sólo no puede hacer que vivan las Naciones

esplendorosamente; las que revivir quieran

la Edad de Oro, han de librarse

de la honradez como de las bellotas. ${ }^{53}$

A partir de esta fábula y de los ensayos que componen la parte primera de la obra, ${ }^{54}$ Mandeville desarrolla su tesis de que el vicio, el interés y el egoísmo son el fundamento de la prosperidad y de la felicidad. En la Introducción ${ }^{55}$ ofrece algunas claves de su intención: "demostrar que las pasiones de las cuales todos decimos avergonzarnos son, precisamente, las que constituyen el soporte de una sociedad próspera”. En el Prefacio dice que el propósito de la obra es mostrar la imposibilidad de hacer compatible las comodidades que ofrece la vida en las sociedades prósperas, ricas y caracterizadas por la codicia con la virtud, porque el vicio es inseparable del poder y de la riqueza. Lo que hace del hombre un animal sociable no es la piedad, la afabilidad, el deseo de compañía u

${ }^{47}$ Ibid.,p. 17.
${ }^{48}$ Ibid.
${ }^{49}$ Ibid.p. 18.
${ }^{50}$ Ibid.,p. 19.
${ }^{51}$ Ibid.,p. 19.
${ }^{52}$ Ibid.,p. 21.
${ }^{53}$ Ibid.
${ }^{54}$ Especialmente: "Investigaciones sobre el origen de la virtud moral"; "Ensayo sobre la caridad y las Escuelas de caridad";
"Investigación sobre la naturaleza de la sociedad" (MANDEVILLE, B., la fábula de las abejas, op. cit., pp. 23-33; 165-216, 216-249). 
otras falsas apariencias, sino que son sus características más viles y odiosas las más necesarias para equipar a las sociedades de grandeza, esplendor y felicidad. ${ }^{56}$

El presupuesto subyacente a esta intencionalidad es que el hombre, además de piel, carne y huesos, está compuesto por varias pasiones que, a medida que se las provoca, van saliendo todas a la superficie y "lo gobiernan por turno quiéralo o no".${ }^{57}$ Mandeville no pretende decir simplemente con esta fábula que toda maldad tiene algo de bueno y que esto bueno contrarresta ese mal. La paradoja sólo queda esclarecida a partir de la definición de virtud, que recapitula en una sola las dos concepciones que eran propias del pensamiento de la época: la definición trascendente o teológica de virtud y la definición racionalista.

Según la concepción teológica común, y tomada en la época de Mandeville como la ortodoxa, la virtud es la aspiración al sumo bien y la superación de la negatividad de la naturaleza corrompida que se logra por la gracia divina. ${ }^{58}$ Era una mentalidad muy extendida la idea ascética de que la naturaleza humana es incapaz de alcanzar la virtud si no es asistida por la gracia divina, y sólo puede alcanzarse la virtud cuando se domina y controla la naturaleza humana. Desde esta negatividad del hombre caído, en la virtud no cabe elemento alguno de egoísmo o de deseo. La virtud consiste, sobre todo, en la negación de sí mismo o en el ejercicio de una acción que es contrario al impulso de la Naturaleza. Consiste, por tanto, en llevar una vida acorde con las virtudes cardinales y con sujeción a las necesidades básicas.

El racionalismo ético insistía en que eran virtuosos aquellos actos que obedecían a la razón, quedando fuera las emociones, los sentimientos o las preferencias personales. En la época de Bernard Mandeville, Nathanael Culverwell ${ }^{59}$ y Richard Price ${ }^{60}$ reafirmaban la idea de que la ley moral se funda en el intelecto y no en la sensibilidad y se hace muy explícita la antítesis existente entre la razón y el impulso natural. Este racionalismo difícilmente podía evitar dejarse afectar por el ascetismo teológico, entonces de moda, y por la condena del impulso natural, teniendo en cuenta que muchos de estos racionalistas eran teólogos. En esta clave hay que entender la crítica que formuló el filósofo Berkeley (obispo de Cloyne) contra Mandeville en su Alciphron. ${ }^{6 l}$

El concepto de virtud que manejaba Mandeville, y que se refleja en la fábula, es una mezcla de ambas concepciones, combinando el rigorismo ascético (teológico) con la ordenación de la conducta a la razón (racionalismo), desvinculada de los instintos naturales. Esto explica que ofrezca la siguiente definición de virtud:

\footnotetext{
${ }^{55}$ Ibid.p. 22.

${ }^{56}$ Prefacio, en Fábula de las abejas, op. cit., pp.5 y 6.

${ }^{57}$ Ibid.

${ }^{58}$ Tanto católicos como protestantes (sobre todo los luteranos, calvinistas y puritanos) compartían la visión platónico-agustiniana del hombre caído.

${ }^{59}$ CULVERWELL, N., An Elegant and Learned Discourse of the Light of Nature(1652), ed. R.A. Greene and H. MacCallum, Toronto, 1971.

${ }^{60}$ PRICE, R., A Review of the principal Questions in Morals (1758), ed. D.D. Raphael, Oxford, 1974.
} 
"cualquier acto por el cual el hombre, contrariando los impulsos de la naturaleza, procura el bien de los demás o el dominio de sus propias pasiones mediante la racional ambición de ser bueno". ${ }^{62}$ Esta definición rigorista de virtud, mezcla de ascetismo y racionalismo, toma igualmente por viciosa toda conducta que no sea el resultado de una negación absoluta de la naturaleza emocional, puesto que la verdadera virtud es desinteresada y desapasionada.

Mandeville proyecta este esquema rigorista (ascético-racionalista) de la virtud sobre la realidad humana y social, y advierte, como diagnóstico, que en ningún sitio encuentra una acción virtuosa, es decir, una acción que sea dictada exclusivamente por la razón y esté exenta de egoísmo. En suma, en ningún sitio se encuentra la virtud y, desde este punto de vista rigorista, toda acción resulta ser viciosa. De aquí se extrae como inmediata consecuencia paradójica que si todas las acciones son del todo viciosas y las cosas provechosas proceden de causas o factores viciosos, entonces los vicios privados (provenientes de acciones individuales) proporcionan beneficios públicos o hacen la prosperidad pública. O bien puede decirse que los beneficios públicos están basados en vicios privados, de forma que si quitásemos éstos desaparecerían aquellos, como queda reflejado, según se ha visto, en la moraleja de la fábula: fraude, lujo y orgullo deben vivir mientras disfrutemos de sus beneficios". 63

Mandeville llevó al absurdo el punto de vista rigorista (ascético) de la virtud que era la concepción dominante en su tiempo (sólo es virtuoso el comportamiento no contaminado de egoísmo, ventaja o utilidad). Lo absurdo consiste en tener que concluir algo que chocaba abiertamente a los oyentes. Es decir, si tal es la noción de virtud, entonces se refleja en el espejo del auditorio algo que no le gusta oír: que los vicios privados se convierten en beneficios públicos.

Este rigorismo moral, que concibe lo bueno como un valor independiente de las circunstancias y que propugna la obediencia a principios, pero no a los resultados, es una actitud moral que se puede percibir en la mentalidad del hombre común. Pero a este hombre común que mantiene ese rigorismo se le puede conducir a la paradoja de la fábula: que los vicios privados se convierten en bienes públicos. Pero este rigorismo, desde el que se hace la argumentación ad absurdum es en realidad algo que no compartía Mandeville, ya que mantenía una posición empirista y huía de todo aquello que trascendiera la experiencia humana. Su sentimiento personal era anti-ascético y anti-rigorista, y se esforzó en demostrar "la irreconciliabilidad de este rigorismo con toda manifestación de civilización". ${ }^{64}$ Mandeville era, por tanto, en teoría (desde el punto de vista que era necesario adoptar para la reducción al absurdo de la fábula) un rigorista ascético (en la virtud no hay mezcla de egoísmo), pero en la práctica era un utilitarista o un maquiavélico. Este aspecto utilitarista queda destacado en su Modest

\footnotetext{
${ }^{61}$ BERKELEY, G., Alciphron or the Minute Philosopher, Londres, 1732. Se trata de una obra apologética del cristianismo dirigida contra los librepensadores, en forma de diálogos.

${ }^{62}$ MANDEVILLE, B., La fábula de las abejas, op. cit,.p. 27.

${ }^{63}$ Ibid., p. 21

${ }^{64}$ KAYE, F.B., Introducción, en La fábula de las abejas, op. cit,. p. XXXIV.
} 
Defence of Public Stews $(1724)^{65}$ :

"Es el absurdo más grosero y una perfecta contradicción en los términos, afirmar que un gobierno no puede cometer deliberadamente el mal para que resulte el bien; pues si un acto público, tomadas en consideración sus consecuencias, produce una mayor cantidad de bien, podría y debería ser calificado de acto bueno". ${ }^{66}$

En esta clave utilitarista hay que entender también el significado de la fábula. En efecto, Mandeville no dice que los vicios no hayan de castigarse cuando se conviertan en delito, sino que ${ }^{67}$ el vicio útil (que no sería, en realidad vicio para los que no fueran rigoristas o ascetas morales) debería fomentarse, pero el vicio dañino ha de perseguirse siempre. ${ }^{68}$ Mandeville nunca sostuvo que todos los vicios fueran igualmente útiles para la sociedad, a pesar de la muchas críticas que al respecto se hicieron sobre la fábula. Tampoco creía Mandeville que debiera estimularse el vicio, sino que creía que algunos vicios si son "manejados diestramente por un político hábil pueden trocarse en beneficios públicos ${ }^{69}$.

En conclusión, la reductio ad absurdum de la fábula, a que antes nos hemos referido, puede contemplarse de tres maneras:

1. En primer lugar, se llega al absurdo si partimos de la tesis rigorista o ascética de la virtud: si todas las acciones son viciosas, los resultado beneficiosos que se producen hay que atribuírselo a los vicios. Los vicios se tornan en beneficios y si se hicieran desaparecer los vicios desaparecería todo el bienestar de que se disfruta.

2. Mandeville no comparte una posible segunda reducción al absurdo: si gracias al vicio se obtiene todo lo bueno del mundo habrá que procurar ser vicioso, ya que una depravación de este tipo no es vicio sino virtud. Mandeville, como se ha dicho, no admite que la utilidad del vicio anule su maldad, y afirma que el vicio dañino ha de perseguirse. Como se dice en la moraleja de la fábula " es beneficio el vicio cuando la justicia lo poda y limita”. ${ }^{70}$

3. Mandeville tampoco comparte una posible tercera reducción al absurdo: puesto que la prosperidad nacional está basada en la depravación hemos de renunciar a esta prosperidad y sacrificar nuestras vidas en aras de la virtud. Esta sería la conducta ideal, pero este ideal es irrealizable. Lo que en realidad dice Mandeville en la fábula es que hay que abandonar todo intento de "hacer de un gran panal un panal

\footnotetext{
${ }^{65}$ En la traducción francesa: "Venus la populaire" (1727). Cfr. La fábula de las abejas. op. cit. p. 279, nota 59.

${ }^{66}$ KAYE, Ibid., p. XXXVIII.

${ }^{67}$ "Cuando afirmo que los vicios son inseparables de las sociedades grandes y poderosas y que sin ellos no podrían subsistir su riqueza ni su grandeza, no quiero decir que cada miembro de ellas, que sea culpable de algún vicio, no deba ser continuamente castigado por ellos, cuando se convierten en delitos." La fábula de las abejas, Prólogo, op. cit., p. 9.

${ }^{68}$ Mandeville escribió su Enquiry into the Causes of the Frequent Executions at Tyburm (1725) sobre la manera más eficaz de impedir el crimen.

${ }^{69}$ La fábula de las abejas, op. cit., p. 248.

${ }^{70}$ Ibid., p. 21.
} 
honrado" ${ }^{71}$

La verdadera tesis de la obra no es que todo mal sea un beneficio público, sino que cierta porción útil de mal (a la que se llama vicio) se convierte en beneficio público.

Hay que concluir diciendo que todos los actos humanos son, en el fondo, viciosos, porque si se hurga en dichos actos, aunque aparentemente puedan ser desinteresados, hay en ellos alguna manifestación o variedad de egoísmo. Desde el ascetismo ético, toda acción cuyo móvil sea un impulso natural se torna viciosa. Como es irreconciliable este rigorismo ético con los principios que gobiernan el mundo o con la realidad de la naturaleza, hay que concluir que hasta lo más valioso y agradable es consecuencia del vicio y así surge la paradoja: los vicios se tornan en beneficios. Desde el punto de vista rigorista y dado el absurdo a que conduce habrá que concluir diciendo que ese modo de entender la virtud, al margen de todo interés, es imposible y, además, es indeseable.

Mandeville se expresa de un modo franco, pero en tono cínico y humorístico. Después de tres siglos, sigue resultando provocador y no mengua su capacidad de irritar a quienes no están de acuerdo con él.

La paradoja que planteó a sus contemporáneos La fábula de las abejas fue un gran incentivo para la búsqueda de soluciones. La provocación, el cinismo y la ironía lograron que a partir de 1723 La fábula de las abejas adquiriera una gran fama y una enorme popularidad, tanto en Inglaterra como en el resto de Europa, sobre todo en Francia y en Alemania. Las críticas a la obra arreciaron y tanto los periódicos como gran número de libros publicados tomaron esta obra como el objeto de sus diatribas. Pero los muchos ataques que se dirigían contra la obra no solo eran síntomas del impacto que el libro ejerció sino que también sirvieron para difundir la fama de su autor. El elevado número de autores importantes que prestaron atención a Mandeville y el enorme catálogo de referencias hechas a su obra ${ }^{72}$ son datos suficientes del alcance que tuvo y cuya proyección en el presente sigue llamando la atención.

\section{BUSCAR EL "PULCHRUM \& HONESTUM" ES COMO PERSEGUIR UNA QUIMERA Y LAS VIRTUDES TRANQUILAS DE SHAFTESBURY SOLO VALEN PARA CREAR ZÁNGANOS.}

Durante la primera mitad del siglo XVIII hubo un grupo de filósofos de la moral ${ }^{73}$ que se opusieron a la interpretación hobbesiana -después retomada por Mandeville- que concebía al hombre como un ser esencialmente egoísta. Frente a la idea de Hobbes de que la fuente de la moralidad social es la autoridad de Estado, estos autores se oponían a cualquier concepción autoritaria de la ley moral y de la obligación ética, bien procediera

\footnotetext{
${ }^{71}$ Ibid.

${ }^{72}$ Baste ver el abultadísimo Catálogo ordenado cronológicamente de las referencias a la obra de Mandeville desde 1716 a 1922 (KAYE, Ibid.,pp. 659-696).

${ }^{73}$ Sobre todo, además de Shaftesbury y Hutcheson, hay que citar a Butler, Hartley, Tucker o Paley.
} 
ésta de Dios o de las leyes del Estado. Todos insistían en la naturaleza social del hombre y todos propiciaron una interpretación social de la moralidad, haciéndola depender de un fin social más que privado.

En este contexto de la Filosofía moral hay que situar al tercer Conde de Shaftesbury (1671-1713) ${ }^{74}$ que concebía al hombre como un ser social al que se vinculan las ideas morales que le son connaturales. Pero esta dimensión social no es una negación de la tendencia individual del hombre a su propio bien a cuya realización se ve empujado por su propia naturaleza. ${ }^{75}$ En la propia estructura de la naturaleza humana se encuentran las inclinaciones, los afectos y las preferencias, de forma que el bien individual del hombre consiste en la armonía y equilibrio de los apetitos, pasiones y afectos controlados por la razón. Pero todo ser humano forma parte de un sistema, es decir, en tanto que es un ser social por naturaleza, esos afectos y pasiones no estarán en armonía hasta tanto no coincidan con el fin social de la comunidad en que vive. No se excluyen, pues, entre sí, ni están obligados a elegir entre egoísmo o benevolencia, preocupación por el propio bien y por el bien público. Habrá que rechazar el egoísmo por nocivo o vicioso sólo si hay una tendencia excesiva al bien privado que no coincida con el interés público, o si hace a un individuo incapaz de ninguna acción generosa ordenada al bien común. La benevolencia ${ }^{76}$ es, por tanto, parte integrante de la moralidad y tiene sus raíces en la naturaleza del hombre, pero no constituye el contenido íntegro de la moralidad, ya que en la naturaleza humana se encuentran compensados los impulsos egoístas y los benevolentes.

Para Shaftesbury la tendencia a la sociabilidad es algo connatural a la estructura del ser humano y no es fruto de artificio alguno. La socialidad del hombre antecede a todo pacto positivo o político y se basa en la constitución social del individuo y consiste en una afección social natural, de modo que lo antinatural es lo antisocial. La justicia y la honestidad son previas a la existencia de cualquier pacto o contrato, de modo que "quien antes de un contrato estaba dispuesto a cometer alguna villanía lo estará con el contrato hecho cuando lo crea conveniente, y quien es bellaco por naturaleza será un bellaco civil". ${ }^{77}$ El análisis de la naturaleza en general y de la naturaleza humana en particular muestra que el hombre es un ser social, colectivo e histórico.

En su obra An Inquiry Concerning Virtue in two Discourses, ${ }^{78}$ Saftesbury busca las raíces de la conducta moral y social del hombre no en la esperanza o el miedo de la recompensa en la otra vida, sino en un sentido moral

\footnotetext{
${ }^{74}$ Fue nieto del que fue protector de Locke y discípulo de éste entre 1686-1689. Para una cronología completa de la vida y obras de Shaftesbury: ANDREU, A., "Estudio introductorio", en SHAFTESBURY, Sensus comunnis. Ensayo sobre la libertad de ingenio yhumos, Valencia, Pre.Textos, 1995, pp. 31-64.

${ }^{75}$ Cfr. Characteritics of Men, Manners, Opinions, Times (1711). Esta obra contiene una serie de tratados y disquisiciones de carácter ético. Véase la nomenclatura de las fuentes de Shaftesbury en ANDREU , A., Estudio introductorio de SHAFTESBURY, Sensus communis, op. cit., p. 21.

${ }^{76}$ Sobre la benevolencia ya nos hemos ocupado:SALGUERO, M.,La benevolencia. Genealogía de una virtud ilustrada, Editorial Universidad de Granada, Geanada, 2011, passim.

${ }^{77}$ SHAFTESBURY, Sensus communis, op. cit., p. 176.

${ }^{78}$ SHAFTESBURY (3rd Earl of) (Anthony Ashley Cooper), An Inquiry Concerning Virtue in two Discourses: I Of Virtue and the belief of a Deity; II Of the Obligations to Virtue, London, 1699.
} 
que lo impulsa a hacer el bien y a promocionar el bienestar de toda la humanidad. Dice Shaftesbury que las tendencias afectivas de una criatura hacia el bien de la especie o de la naturaleza común le es tan propia y natural como la función que desempeña el estómago para digerir, los pulmones para respirar o las glándulas para segregar jugos. Shaftesbury asimila la moral al sentido estético, de forma que lo mismo que hay un sentido para captar lo bello, lo feo, lo odioso o lo despreciable, hay también un sentido moral enraizado en la naturaleza humana, un sensus communis que es "esa suerte de civilidad que brota de un justo sentimiento de los derechos comunes de la humanidad y de la igualdad natural que hay entre los hombres de la misma especie" ${ }^{79}$ Este sensus communis es el espíritu público que "no puede venir más que de un sentimiento social asentado del consorcio con el género humano".$^{80}$ En su Carta sobre el entusiasmo $(1708){ }^{81}$ dice Saftesbury que existe un "entusiasmo natural" por el bien público a modo de pacto natural originario.

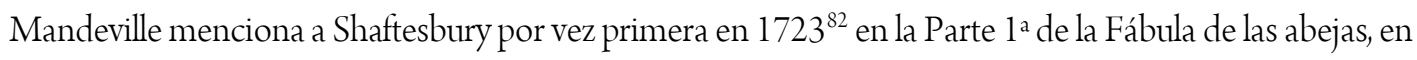
el ensayo titulado "Investigaciones sobre la naturaleza de la sociedad". ${ }^{33} \mathrm{Al}$ comienzo de este ensayo, Mandeville recapitula la posición de Shaftesbury y concluye diciendo que "no puede haber dos sistemas más opuestos que el de Su Señoría y el mío" ${ }^{84}$ Se refiere Mandeville en concreto a las Characteristics de Shaftesbury en donde, según su análisis, los hombres pueden ser naturalmente virtuosos y puesto que están hechos para la sociedad imagina que han de nacer con un bondadoso afecto para con el conjunto del cual forman parte "y con una propensión a promover el bien del mismo" ${ }^{85}$ Pueden sacarse algunas consecuencias, a juicio de Mandeville, de esta suposición: será virtuosa toda acción realizada con el propósito de contribuir al bien público y será vicio toda acción egoísta completamente ajena a esa intención. Además, según Shaftesbury, ${ }^{86}$ cualquier moda, ley, costumbre o religión, por mala y viciosa que sea en sí misma nunca podrá alterar la naturaleza independiente e inmutable del mérito y la virtud. Imagina, además Shaftesbury, a juicio de Mandeville, que "una persona de inteligencia sólida, observando las reglas del sentido común, no solamente puede descubrir ese pulchrum \& honestum, tanto en la moral como en las obras del arte y de la naturaleza, sino también gobernarse a sí misma con su propia razón, con la misma facilidad y habilidad con que un buen jinete maneja de la brida a un caballo bien amaestrado". ${ }^{87}$ El diagnóstico de Mandeville sobre esta tesis de Shaftesbury -que choca frontalmente con su posición-lo expresa del siguiente modo no sin ironía:

\footnotetext{
${ }^{79}$ SHAFTESBURY, Sensus communis, op. cit., p. 172.

${ }^{80}$ Ibid.,p. 173.

${ }^{81}$ Cfr. ANDREU, A., Estudio introductorio, op. cit., p. 52.

${ }^{82}$ Cuando Mandeville publicó El panal Rumoroso en 1705 y cuando en 1714 escribió La Fábula no hay razón para suponer que ni siquiera hubiera leído a Shaftesbury, y hasta 1723 no es mencionado en la Fábula. KAYE, Introducción, op. cit., p. XLVI.

${ }^{83}$ La fábula de las abejas, op. cit., pp. 165-248.

${ }^{84}$ Ibid., p. 216.

${ }^{85}$ Ibid.

${ }^{86}$ Characteristicks, ed. Robertson, 1900, I.
} 


\begin{abstract}
"Admito que sus ideas son generosas y refinadas, altamente halagüeñas para el género humano y capaces, con un poco de entusiasmo, de inspirarnos los más nobles sentimientos hacia la dignidad de nuestra levantada naturaleza. Lástima que no sean acertadas. Si no hubiese demostrado yo, casi en cada página de este tratado, que su solidez es inconciliable con nuestra diaria experiencia, no diría lo que afirmo; (...) me propongo (...) convencer al lector no sólo de que no son las cualidades buenas y amables del hombre las que le hacen superior, como criatura sociable, a otros animales, sino, además, de que sería de todo punto imposible educar a las multitudes de una nación rica, populosa y floreciente, o una vez educadas mantenerlas en tal condición, sin ayuda de lo que llamamos el mal, tanto natural como moral". ${ }^{88}$
\end{abstract}

A lo largo de las Investigaciones sobre la naturaleza de la sociedad, Mandeville refuta las tesis de Shaftesbury, siguiendo una metodología empírica y con un estilo brillante, cargado de intencionalidad retórica y no exento de ironía, Así, dice que buscar ese pulchrum \& honestum "es como perseguir una quimera", aunque aún es peor la hipocresía a que conduce la noción imaginaria de que el hombre puede ser virtuoso sin abnegación. ${ }^{89}$ Sin los vicios, "la excelencia de la especie habría permanecido siempre oculta y toda persona ilustre que se haya hecho famosa en el mundo es una rotunda evidencia en contra de ese simpático sistema". ${ }^{90} \mathrm{Al}$ referirse a las virtudes tranquilas recomendadas por Shaftesbury decía de ellas que "no valen más que para crear zánganos y podrían cualificar a un hombre para los estólidos goces de la vida monástica o, a lo sumo, para juez de paz rural, pero nunca (...) Ie impulsarían hacia los grandes logros y las empresas audaces y peligrosas. ${ }^{91}$

Mandeville estaba convencido de que las pasiones profundamente arraigadas en el hombre tales como la comodidad, el ocio y la propensión a disfrutar de los placeres sensuales no se curan con preceptos. Las costumbres e inclinaciones profundamente arraigadas "sólo pueden dominarse con pasiones de violencia mayor". ${ }^{22} \mathrm{Si}$ se examinan los hechos con precisión se descubre, según Mandeville, que, al atribuir los comportamientos favorables a la amistad o a la cooperación, a la sociabilidad y a su natural inclinación a la benevolencia, es una falsa realidad pues lo que ocurre es que "sólo tratamos de fortalecer nuestro interés". Además, lo que sea "pulchrum \& honestum" queda sometido a los variables usos y costumbres, por lo que "las generosas ideas relativas a la bondad natural del hombre son dañosas, porque tienden a desorientar, y resultan meramente quiméricas: la verdad de esto último la he ilustrado con los ejemplos más evidentes sacados de la historia”. ${ }^{33} \mathrm{Al}$ final de este ensayo, Mandeville expresa con nitidez su posición frente a Shaftesbury:

"Me congratulo de haber demostrado que ni las cualidades amistosas ni los afectos simpáticos que son naturales en el hombre, ni las virtudes reales que sea capaz de adquirir por la razón y la abnegación, son los cimientos de la sociedad; sino que, por el contrario, lo que llamamos mal en este mundo, sea moral o natural, es el gran principio que hace de

\footnotetext{
87 “Investigación sobre la naturaleza de la sociedad”, en La fábula de las abejas, op. cit., p. 216.

${ }^{88}$ Ibid., pp. 216-217.

${ }^{89}$ Ibid.,p. 221.

${ }^{90}$ Ibid., p. 223.

${ }^{91}$ Ibid., p. 222.

${ }^{92} \mathrm{Ibid}$.

${ }^{93}$ Ibid., p. 229.
} 
nosotros seres sociales, la base sólida, la vida y el sostén de todos los oficios y profesiones, sin excepción: es ahí donde hemos de buscar el verdadero origen de todas las artes y ciencias, y en el momento en que el mal cese, la sociedad se echará a perder si no se disuelve completamente". ${ }^{94}$

La confrontación de las posiciones de Shaftesbury y Mandeville no sólo se pone al descubierto en el antagonismo del punto de partida, sino también en las actitudes que motivaron su pensamiento. Esta confrontación era evidente para Mandeville y, por eso, al sentirse concernido de manera directa, formuló su réplica frente a Shaftesbury. Mientras que para este último la coincidencia entre beneficios públicos y privados se debe a una benevolencia ilustrada, para Mandeville esa coincidencia era el resultado de un estrecho egoísmo. Mientras que Mandeville consideraba a los hombres gobernados ineludiblemente por la pasión egoísta, Shaftesbury los consideraba dotados de sentimientos benevolentes. Es decir, al egoísmo como esencia de la naturaleza humana (Mandeville) se enfrenta la esencial benevolencia y la fe en el altruismo (Shaftesbury).

\section{LAS PRECAUCIONES DE HUTCHESON ANTE EL MOLESTO ESPEJO DE LA FÁBULA DEMANDEVILLE.}

Aunque de origen escocés, Hutcheson (1694-1746) nació y vivió en el norte de Irlanda hasta 1711, ejerciendo como pastor presbiteriano durante algún tiempo. Nieto de escocés y nacido en el condado de Down, era un liberal presbiteriano educado en Belfast y Glasgow que durante un tiempo asistió a una academia de disidentes de Dublín donde se convirtió en miembro del grupo de intelectuales progresistas reunido en torno a Robert Molesworth, un diplomático protegido de John Locke. Fue perseguido en dos ocasiones mientras enseñaba en su academia de Dublín y fue procesado por herejía mientras impartía clase en Glasgow. ${ }^{95}$ Entre 1725-1726 publicó seis cartas en el Dublín Journal en las que criticaba a Hobbes y a Mandeville, iniciándose a parir de entonces su vida intelectual. En 1730 se le ofreció un puesto de profesor de Filosofía moral en la Universidad de Glasgow donde enseñó y fijó su residencia. En esta universidad tuvo alumnos destacados: A, Smith, D. Hume y A. Ferguson, entre otros. Al movimiento intelectual de esta época se le ha denominado Ilustración escocesa que se caracterizó por mantener un estrecho contacto con la filosofía racionalista del continente, sobre todo con Holanda, Alemania y Francia. ${ }^{96}$

Hutcheson -que enseñó a Hume buena parte de lo que sabía, influyó en los escritos precríticos de Kant y en Adam Smith- era un republicano harringtoniano que adoptó una línea liberal radical en apoyo de los oprimidos

\footnotetext{
${ }^{94}$ Ibid., p. 248.

${ }^{95}$ EAGLETON, TERRY, Los extranjeros. Para una ética de la solidaridad, trad. Antonio Francisco Rodríguez Esteban, Barcelona, Paidós, 2010, p. 70

${ }^{96}$ Cfr. SCOTT, W.R, Francis Hutcheson. His Life, Teaching and Position in the History of Philosophy, Nueva York, Augustus M. Kelley, 1966.
} 
para derrocar un régimen injusto y ejerció una gran influencia en Thomas Jefferson. ${ }^{97}$ Era un humanista cívico que defendía la igualdad natural de todos los seres humanos y estaba convencido de que el bien público constituye el propósito moral más elevado. Su logro más innovador consistió en trasladar el lenguaje del republicanismo clásico (poniendo el énfasis en el deber, el espíritu público y la responsabilidad política) al discurso de la ética y de la psicología del siglo XVIII. ${ }^{98}$

En An Essay on the Nature and Conduct of the Passions and Affections with Illustrations on the Moral Sense (London, 1728) reconoce que no ha de haber necesariamente un antagonismo entre el propio interés y el interés público. Fue un antagonista de Hobbes y afirmaba que el estado de naturaleza era un estado de libertad y no de anarquía. Los escritos de Hutcheson constituyen una alternativa antropológica a la tesis del interés egoísta de Hobbes y de Mandeville. Decía en Reflections upon Laughter que Hobbes "ha pasado por alto todo cuanto en la humanidad es bueno o generoso; y representa a los hombres bajo el prisma en que los observaría un bellaco que sospechara que toda amistad, amor y afectos sociales corresponden a hipocresía, cálculo, egoísmo o miedo".99

Hasta tal punto necesitaba Hutcheson esgrimir sus tesis contra las de Mandeville que en el título de su Inquiry ${ }^{100}$ incluye una referencia al autor de La fábula de las abejas. En esta obra Hutcheson se dedicó a exponer y a defender los principios de Shaftesbury en contra de los de Mandeville. En una tarea de desenmascaramiento, Mandeville ponía en evidencia que tras el concepto habitual de virtud se ocultan pasiones e intereses privados que promueven la prosperidad y producen beneficios públicos. Esta mentalidad representa paradigmáticamente al liberalismo más radical que en boca de Mandeville sostiene que el mundo es un lugar donde nuestros intereses negocian y llegan a acuerdos y es posible, siguiendo a Mandeville, imaginar una sociedad desarrollada y civilizada bajo la exclusiva tutela del egoísmo. ${ }^{101}$

Hutcheson toma precauciones para no aproximarse a ese panal rumoroso de que habla Mandeville pues es consciente de que, a veces, resulta difícil percibir el motivo de la inclinación que lleva al agente a actuar, y puede ser que creamos que el motivo de la acción sea la benevolencia cuando es en realidad el interés. Para diferenciar su posición de la de Mandeville, Hutcheson acude ${ }^{102}$ en Una investigación sobre el sobre el origen de nuestra idea de virtud al sentido moral que es aquel que nos inclina naturalmente hacia la benevolencia y consiste en elegir el bien

\footnotetext{
${ }^{97}$ EAGLETON, TERRY, op. cit.p. 76.

${ }^{98}$ Ibid., p. 68.

${ }^{99}$ HUTCHESON. F., Reflections upon laughter, and Remarks upon the Fable of the Bees, Glasgow, 1750, p. 6. La traducción está tomada de EAGLETON, T., op. cit., p. 72,

${ }^{100}$ HUTCHESON, F., Inquiry into the Original of our Ideas of Beauty and Virtue; in Two Treatises, in which the Principles of the Earl of Shaftesbury are Explain'd and Defended, against the Author of the Fable of the Bees: And the Ideas of the Moral Good and Evil are establish'd according to the Sentiments of the Ancient Moralists etc, London, 1725.

${ }^{101}$ SEONAE PINILLA, J., Estudio introductorio, en HUTCHESON, F., Escritos sobre la idea de virtud y sentido moral, trad. Aurora Lauzardo, Madrid, Centro de Estudios Políticos y Constitucionales, 1999.p. XXXI.

${ }^{102}$ HUTCHESON, F., Escritos sobre la idea de virtud y sentido moral, I.- Una investigación sobre el origen de nuestra idea de virtud, trad. Aurora Lauzardo, op. cit,, secciones I y II, pp. 9-41.
} 
al margen de cualquier interés complaciéndose con la felicidad de los demás. Hutcheson sabe que el término sentido se utiliza habitualmente para hacer referencia a la visión o al tacto, pero cree que está justificada la ampliación del uso del término "sentido", ya que la mente puede ser afectada pasivamente no sólo por objetos sensibles en el sentido ordinario del término, sino también por objetos de orden estético y moral.

Hutcheson -a quien la tesis de Mandeville del egoísmo le resulta del todo desagradable- sostiene que por naturaleza somos sociables y buenos tanto como egoístas y malvados. Lo que ocurre es que ante la disyuntiva nos complacemos más en las virtudes que e los vicios, dada su convicción de que existe un estado del espíritu, "que podríamos denominar empático, según el cual cuando vemos a alguien que sufre o en un estado de miseria, volvemos hacia él nuestros pensamientos y sentimos piedad y ganas de aliviar su pena”. ${ }^{103}$ Hutcheson formula, en definitiva, un sistema moral alternativo al de Mandeville. La benevolencia desinteresada pensada para el bien de los demás es el punto de vista opuesto a la enseñanza que se desprende de La fábula de las abejas, según la cual debajo de toda acción virtuosa late siempre un interés vicioso.

Siguiendo a Shaftesbury, Hutcheson no soporta la imagen de los seres humanos convertidos en un fardo de inclinaciones o de intereses que negocian, sino que los concibe como seres socializados e inclinados por naturaleza al bien como también nos inclinamos naturalmente hacia la belleza o hacia la imagen perfecta del mundo. Aun en el caso de que tuviera razón Mandeville sería preferible desarrollar la benevolencia porque promete un bien público más seguro que el que ofrece el egoísmo del panal. Ningún hombre querrá verse reflejado el molesto espejo de la fábula si puede verse reconocido "en el mucho más amable de la benevolencia". ${ }^{104}$ Nadie podrá complacerse en una imagen de la naturaleza humana desagradable, fea y violenta. Más bien puede pensarse que la mayoría -si fuera preguntada- preferiría un mundo más hermoso, menos violento y más benevolente.

El mundo representado por Hobbes, Bayle, Mandeville y posteriormente otros como La Rochefoucauld ${ }^{105}$ es injusto, según Hutcheson, con la humanidad misma. Si no hubiera un sentido moral -argumenta Hutcheson en System of Moral Philosophy (1728)- en nuestra constitución, si fuéramos tan egoístas como argumentan esos autores, la vida humana sería muy diferente a como la sentimos cada día, sin alegría, sin amor, fría, un completo estado de argucias y sospechas. ${ }^{106}$ Pero la fundamentación de Hutcheson contra Mandeville -que es también el

\footnotetext{
${ }^{103}$ SEOANE PINILLA, op. cit., p. XXXIII.

${ }^{104}$ SEOANE PINILLA, op. cit., p. XXXIIII.

${ }^{105}$ Cfr. TODOROV, T., La vida en común. Ensayo de antropología general, Madrid, Taurus, 1995, pp. 20-22.

${ }^{106}$ SEAONE PINILLA, op. cit., p. XXXV. Dice este autor que peor aún que el miedo hobbesiano al asalto o a la emboscada en el camino es lo siniestro, es decir, la posibilidad de un mundo donde nos de igual si los hombres y mujeres que nos rodean están vivos o muertos siempre que estén debidamente controlados por las leyes. Lo siniestro es la imposibilidad de la benevolencia: el olvido de exigir que cada acto sea algo más que una mera comunicación para interactuar, y el miedo de Hutcheson consiste en que ideas como la de Hobbes nos lleven, como de hecho nos han acercado en numerosas ocasiones, a lo siniestro. Eso sí que es feo y poco placentero.
} 
rechazo de la línea hobbesiana y del liberalismo clásico- no va más allá de esa exhortación hacia la benevolencia como el otro ingrediente que la naturaleza humana genera espontáneamente y del que se olvida Mandeville. Se trata de una apuesta por determinado modo de estar en la sociedad o de un talante lo suficientemente realista como para saber que hay que armonizar dos formas de bienestar: el bienestar de los demás que es un buen requisito para el bienestar propio y el bienestar propio que ha de incluir un deseo por la felicidad de los demás.

En definitiva, el ethos de la Ilustración británica del siglo XVIII constituyó un triunfo del sentimiento sobre los valores de la abnegación y austeridad de la tradición cristiana. ${ }^{107}$ En el trasfondo de la racionalidad ilustrada se aprecia cómo se produce una tensión dinámica entre dos fuerzas que se desajustan: la razón instrumental orientada por el interés y la razón pasional. ${ }^{108}$ En la Ilustración británica se intentan equilibrar ambos principios contrapuestos (interés racional y pasiones): la defensa de los intereses personales no es incompatible con la cooperación y el intercambio de posiciones, ni con la búsqueda de una armonía social capaz de encontrar solución a los conflictos planteados. El análisis social hecho desde el punto de vista del individualismo no es incompatible con una visión social y cooperativa de los seres humanos. Uno de los ingredientes de esa armonía es precisamente el presupuesto de que los individuos disponen, como registro moral, de la inclinación a la simpatía y a la cooperación.

\section{ADAM SMITH Y LA SOFISTERÍA INGENIOSA DE MANDEVILLE.}

La percepción distorsionada que se tiene, a veces, de Adam Smith se debe al hecho de que La riqueza de las naciones $(1776)^{109}$ fue una obra que mereció mucho interés desde el momento de su publicación, ${ }^{110}$ mientras que La teoría de los sentimientos morales (1759) fue mucho menos conocida y hasta 2004 no se había hecho una versión completa de la obra al español. ${ }^{111}$ Tan llamativa asimetría viene a reflejar la percepción equivocada que se tiene de Smith. ${ }^{112}$

La idea más extendida de Smith es que fue el padre de la ciencia económica y del liberalismo a lo que se asocian algunos tópicos: que el mercado libre actúa como una "mano invisible" que maximiza el bienestar, que fue

\footnotetext{
${ }^{107}$ COLOMER, J., Ilustración y liberalismo en Gran Bretaña, en VALLESPÍN, F. (Ed.), Historia de la teoría política, op. cit, p. 15.

${ }^{108}$ Cfr. DE PARAMO ARGÜELLES, J.R., La Ilustración británica, en PECES-BARBA MARTÍNEZ, G., FERNÁNDEZ GARCÍA, E., y DE ASÍS ROIG, R., (Dirs.) Historia de los derechos fundamentales, Tomo I, Siglo XVIII, Vol. I, Madrid, Dykinson, 2001, pp. 168-269.

${ }^{109}$ SMITH, A., An Inquiry into the Nature and Causes of the Wealth of Nations, 2 vols. Oxford, Oxford University Press, 1976. En las citas textuales de esta obra seguiremos la edición de R.H.Campbell y R. Skinner, Investigación sobre la naturaleza y causa de la riqueza de las naciones, trad. Juan Carlos Collado y Antonio Mira-Perceval, 2 vols., Barcelona, Oikos-tau, 1988.

${ }^{110}$ En España hubo varias traducciones a finales del siglo XVIII.

${ }^{111}$ Se trata de la edición de Carlos Rodríguez Braum, Madrid, Alianza Editorial, 2004. Las citas de Smith las haremos por esta edición. Sin embargo, seguiremos muy de cerca el texto original: SMITH, A., The Theory of Moral Sentiments, ed.. RAPHAEL, D.D, y MACFIE A.L., Oxford, Clarendon Press, 1979.
} 
el profeta del "capitalismo salvaje" caracterizado por un mercado sin justicia, ni valores éticos y sólo orientado por el egoísmo. Sin embargo, a quien más indignaría esta descripción sería sin duda al mismo Smith que fue ante todo "un moralista, un admirador de la severidad estoica que se preocupó siempre por las normas que limitan la conducta humana". ${ }^{113}$

Son muchos los autores que coinciden en la apreciación de que, según Smith, la economía en modo alguno está separada de los registros de la moralidad, sino al contrario, hay un ajuste ente ambas dimensiones de la acción humana. ${ }^{114}$ En La Riqueza abundan más las referencias al interés y al deseo de mejorar la condición humana, pero en La teoría de los sentimientos morales también está claramente formulado ese motivo y esos deseos, sobre todo en la parte primera, donde justifica ${ }^{115}$ que, bajo las reglas de la competencia, la persecución del propio interés es bueno para nosotros y también para los demás, al obligarnos a trabajar y a servir a la sociedad.

En el pensamiento moral de la época entraban en confrontación dos visiones de la naturaleza humana, la que giraba en torno al egoísmo (Maquievelo, Hobbes, Mandeville, La Rochefoucauld... ) y la que se sustentaban en la exaltación de la benevolencia (Cumberland, ${ }^{116}$ Shaftesbury, Hutcheson...). Smith adoptará una posición intermedia que se aleja tanto de la tesis del interés egoísta del autor de La fábula de las abejas, como de las virtudes sosegadas de Hutcheson para centrarse en las tendencias naturales del hombres, en especial la simpatía, como condiciones de la socialidad.

Frente al hobbesianismo, Smith reafirma su idea de la sociabilidad natural que expresa que el hombre está atado a la humanidad por los lazos inmediatos del sentimiento y de la compasión, y también expresa que está vinculado a sus conciudadanos por lazos más débiles e inducidos por el cálculo racional y de la utilidad.

Según Smith, hay tres sistemas morales en los que se hace una distinción real entre la virtud y el vicio, cualquiera que sea el contenido de esas cualidades. ${ }^{17}$ Dice Adam Smith de estos sistemas que cualquiera de ellos

\footnotetext{
${ }^{112}$ RODRÍGUEZ BRAUM, C., "Estudio preliminar", en SMITH, A., La teoría de los sentimientos morales, edición y traducción de Carlos Rodríguez Braum, Madrid, Alianza Editorial, 2004, p. 7.

${ }^{113}$ Ibid. p. 8. Como señalaremos posteriormente, los autores que aquí vamos a citar coinciden en esta apreciación de que, según Smith, la economía en modo alguno está separada de los registros de la moralidad, sino al contrario, hay un ajuste ente ambas dimensiones de la acción humana. Entre otros: RAPHAEL, D.D., "Introducción”, en SMITH, A., The Theory of Moral Sentiments, ed. RAPHAEL,D.D., y MACFIE, A.L. Oxford, Clarendon Press, 1979, pp. 20-25.

${ }^{114}$ Entre otros: RAPHAEL, D.D., "Introducción", en SMITH, A., The Theory of Moral Sentiments, ed. D.D. RAPHAEL, y MACFIE, oxford, Clarendon Press, 1979, pp. 20-25. También: HIMMELFARB, G., La idea de la pobreza. Inglaterra a principios de la época industrial, México, Fondo de Cultura Económica, 1988, pp. 55-97.

${ }^{115}$ RODRÍGUEZ BRAUM, op. cit., p. 20.

${ }^{116}$ De este autor me he ocupado: SALGUERO, M., "Inclinación natural a la benevolencia en el pensamiento de Richard Cumberland”, en VV.AA., Historia y Filosofia Polítca, Jurídica y Social. Estudios en homenaje al Profesor Gregorio Peces-Barba, Dykinson, Madrid, 2008, pp. 902-926.

${ }^{117}$ La teoría de los sentimientos morales, op. cit, parte VII, secc. II. Uno de ellos es el sistema según el cual la virtud consiste en la corrección y tiene como virtudes el autocontrol, la continencia, la fortaleza, la independencia de la fortuna y el desprecio por los accidentes exteriores como el dolor o la muerte. Se trata de las virtudes "respetables", y tanto el sistema estoico como el epicúreo son los ejemplos representativos de este sistema (pp. 518-520). En segundo lugar está el "sistema benevolente" que corresponde a las virtudes "moderadas, amables y gentiles" o virtudes del "humanitarismo indulgente". Este sistema estimula "todas esas mansas
} 
presenta algo valioso y especial, y sería buena cualquier sociedad que pretendiera vivir en conformidad con los preceptos de cualquiera de ellos. Pero destaca que hay un sistema, el de Bernard Mandeville, "que elimina por entero la distinción entre el vicio y la virtud" y cuya tendencia es por ello totalmente perniciosa. ${ }^{118}$

Según A. Smith, hay algunas apariencias de verosimilitud "descritas y exageradas por la vivaz y humorística -aunque hasta rústica- elocuencia del Dr. Mandeville, que puede embaucar a los no diestros". ${ }^{119} \mathrm{La}$ tesis de Mandeville se sustancia básicamente, según Smith, en afirmar que lo que se hace por un sentido de la corrección o por consideración a lo que es loable de hace en realidad por amor a la alabanza, por orgullo, por interés, por vanidad, en definitiva por egoísmo. Siempre triunfan las motivaciones egoístas y una de las más poderosas es la vanidad (el deleite por el aplauso). Si alguien parece que sacrifica el propio interés al de sus compañeros, escarbando un poco se verá que es amor propio. En definitiva, "todo empeño cívico, toda preferencia por el interés público antes que el privado, es pura trampa y falsedad, y la virtud humana de la que tanto se alardea y que da lugar a tanta emulación entre las personas es meramente la prole que la adulación engendra en el orgullo". ${ }^{120}$

En la réplica a Mándeville, Smith, además de afirmar que el amor propio puede ser muchas veces un motivo virtuoso para actuar, niega que la vanidad sea fuente de todas las acciones virtuosas. Para refutar esta te sis, se esfuerza por justificar que el deseo de hacer lo que es honroso y noble, o el convertirnos en objetos propios de la estima y aprobación, no puede ser devaluado como vanidad. Puede tildarse de vanidad el anhelar el elogio por cualidades elogiables o bien el darse importancia sin que exista base para ello. La vanidad, sostiene Smith, es propia del necio o del embustero que se atribuye méritos de los que carece. También se puede decir que es culpable de vanidad quien no se contenta cuando se silencia la estima o la aprobación y cuando gustan las expresiones laudatorias, o quien nunca está satisfecho sino cuando "sus propias alabanzas tintinean en sus oídos". ${ }^{121}$ No puede, por tanto, confundirse el deseo de convertirnos en honorables y estimables por merecer verdaderamente esos apelativos con el anhelo frívolo de ser alabados a toda costa. Ciertamente hay afinidad entre "vanidad" y "amor a la gloria verdadera" porque ambas aspiran a la estima y aprobación, pero difieren en que la primera es una pasión injusta o absurda, y la segunda es una pasión justa, razonable y equitativa. ${ }^{122}$ Pero además de la vanidad como fundamento de toda virtud, Mandeville procura subrayar la imperfección de la virtud humana en otros aspectos.

virtudes", pero niega el apelativo de virtud a todos los principios activos egoístas y que sólo atienden al propio interés. El egoísmo desdora el mérito de al benevolencia cuando opera conjuntamente con ella (p. 519). El tercer sistema que distingue al virtud del vicio es aquel en que la virtud consiste en la prudencia y concede el máximo estímulo a la cautela, la vigilancia, la sobriedad o la juiciosa moderación. Este sistema degrada las virtudes amables y elimina la grandeza de las virtudes respetables (p. 519).

${ }^{118}$ La teoría de los sentimientos morales, p. 520.

${ }^{119}$ Ibid.

${ }^{120}$ Ibid.p. 521.

${ }^{121}$ Ibid.p. 522.

122 Ibid.p. 523. 
Así, afirma que lo que suele denominarse como conquista o dominio de las pasiones no es más que un nuevo disfraz de las mismas. Según esto, sería, por ejemplo, lujuria cualquier exceso del mínimo necesario para la naturaleza humana, con lo cual, con indica Smith, "es vicioso hasta el uso de una camisa limpia o una habitación cómoda". ${ }^{123}$ Critica a Mandeville sus razonamientos falaces y llenos de "sofistería ingeniosa", aderezada con ambigüedades del lenguaje. Virtudes como la "templanza" o la "castidad" no exigen para ser tales -como pretende Mandeville- una absoluta insensibilidad ante las pasiones que pretenden controlar. Se trata sólo de reprimir la vehemencia de la pasión del placer para que no se dañe el individuo o la sociedad. ${ }^{124}$

La falacia de La fábula de las abejas estriba en que "representa cualquier pasión como plenamente viciosa, en cualquier grado y cualquier sentido. Por ello trata como vanidad todo lo que haga cualquier referencia a lo que son o deberían ser los sentimientos de los demás, y por medio de esa sofistería establece su conclusión favorita: "los vicios privados son beneficios públicos". ${ }^{125}$ Razona Smith diciendo que si, en efecto, la magnificencia, los adelantos elegantes de la vida, la escultura, la pintura o la música son calificados de lujuria, entonces es cierto que la sensualidad o la ostentación son beneficios públicos, pues sin esas cualidades las artes refinadas no podrían fomentarse y languidecerían. La aporía de este modo de plantear la cuestión reside en presuponer -como ocurría en las doctrinas ascéticas de la época- que las virtudes consisten "en la completa extirpación y aniquilación de las pasiones". ${ }^{126}$ A Mándeville le resulta fácil probar -dice Smith- que esa extirpación nunca tuvo lugar y si tuviera lugar sería pernicioso para la sociedad, porque pondría fin a toda industria o comercio. ${ }^{127} \mathrm{Al}$ decir lo primero parecía demostrado que no existía la virtud (pues la extirpación no se produce y pretender que hay virtud es trampa y engaño), y al afirmar lo segundo se justifica que los vicios privados eran beneficios públicos (pues sin ellos la sociedad no prospera).

El sistema de Mandeville provocó en su tiempo mucho alboroto, según aprecia Smith, aunque no generó más vicio del que había sin él. Pero "proclamó la corrupción de sus motivaciones con una audacia disoluta que no se había conocido hasta entonces". ${ }^{128}$ Pero su sistema no habría podido engañar a tantos ni habría ocasionado tanta alarma "ni no hubiera bordeado en algunos aspectos la verdad". ${ }^{29}$

\footnotetext{
${ }^{123}$ Ibid.p. 526.

${ }^{124}$ Ibid.

${ }^{125}$ Ibid.p. 527.

${ }^{126}$ Ibid. p. 527.

${ }^{127}$ Ibid.

${ }^{128}$ Ibid.p. 528.

${ }^{129}$ Ibid.
} 


\section{ACTUALIDAD DE MANDEVILLE PARA UNA SOCIEDAD COMERCIAL ABIERTA Y LA NECESARIA CRÍTICA DE LA ÉTICA DEL FABULADOR SATÍRICO. UNA REFLEXIÓN CONCLUSIVA.}

Aunque fue un autor incomprendido y no adquirió la relevancia de que disfrutaron David Hume o Adam Smith, puede decirse que Bernard Mandeville fue una de las mentes más incisivas de las tres primeras décadas del siglo XVIII. Con su Fábula de las abejas, Bernard Mandeville formó parte del debate religioso, moral y político de su tiempo, suscitó el interés de muchos de sus contemporáneos, ejerció su influencia como fabulador satírico, y adquirió merecida fama en la cultura europea de la ilustración.

Sus ensayos, sus diálogos y sus fábulas hicieron ver la importancia que habría de tener en el futuro el ámbito de lo público, cuya dinámica habría de verse condicionada por un conjunto de relaciones cívicas que tiene su fundamento en el orden espontáneo o natural de las sociedades y que se constituye en el auténtico móvil de la acción. El dinamismo de la esfera pública estaba necesitado de una moralidad que se mostrara acorde con las exigencias de una sociedad comercial abierta cuyo verdadero resorte había de provenir de la satisfacción de los apetitos, deseos y pasiones que anidan en los registros más originarios de la naturaleza humana.

La actualidad de Bernard Mandeville parece hoy incuestionable porque puede apreciarse en este autor la construcción de un discurso legitimador del libre mercado o de la sociedad de mercado propia del espíritu del capitalismo que con su individualismo posesivo presupone que el propio interés propicia de forma automática o espontánea el bienestar público. Fue un adelantado de la teoría del "laissez faire"a la que se refiere Adam Smith en la Riqueza de las naciones y fue un promotor temprano del desarrollo del utilitarismo moderno y de la división del trabajo. ${ }^{130}$

Mandeville pretendía buscar una vía de legitimación a los intercambios mercantilistas propios de una sociedad comercial abierta y próspera, desactivando la moralidad ascética en torno a la virtud que estaba vigente en su época. Según Mandeville, siguiendo a Pierre Bayle, es posible ser bueno sin necesidad de otorgar a la virtud una dimensión religiosa o trascendente. Para llevar a cabo conductas socialmente cooperativas basta con seguir el propio interés, como quiera que de forma espontánea este interés se convierte en interés público que consiste en el progreso material de la satisfacción de las necesidades. Ese interés público se torna, así, en la virtud pública por excelencia que facilita las transacciones comerciales y armoniza las relaciones mercantiles, creándose de ese modo una conciencia cívica adecuada a una sociedad de mercado. Como subraya Friedrick Hayek, Bernard Mandeville abrió camino en el pensamiento moderno a la idea de que existe un orden espontáneo en la evolución de las

\footnotetext{
${ }^{130}$ Cfr. MANDEVILLE, B., "Diálogo tercero", en Diálogo entre Horacio y Cleómenes, en MANDEVILLE, B., La fábula de las abejas, trad. Ferrater Mora, F.C.E., op, cit.pp. 447-448.
} 
sociedades en un momento en que el racionalismo del siglo XVII ocultaba ese avance. ${ }^{131}$

Bernard Mandeville fue un defensor del lujo, del orgullo, el egoísmo, el afán de dominio y de la ostentación en todas sus manifestaciones y para ello adoptó como recurso satírico el concepto rigorista de virtud que consistía -tal como era percibido en la época- en concebirla como una total negación del yo como quiera que el acto virtuoso se practica por contradicción con los impulsos naturales, dominando así las pasiones. Como era imposible de hecho -dado que no se puede ir contra natura- mantener ese concepto rigorista de virtud, Mandeville obligaba a sus interlocutores críticos a ablandar ese concepto rigorista y a aceptar un criterio de virtud menos exigente y más próximo a la mentalidad utilitarista de aquel tiempo de mentalidad burguesa. Con este recurso irónico, el molesto espejo de la Fábula de las abejas servía de recurso desenmascarador de las acciones humanas como quiera que detrás de toda acción virtuosa de corte rigorista, si se urga lo suficiente, aparece alguna forma del amor propio o del egoísmo.

Frente a la teoría del Estado hobbesiano, Mandeville estaba convencido de que el Estado era un mal necesario, pero no era suficiente para llevar a cabo la tarea civilizatoria de las sociedades humanas organizadas. La fuerza de ese impulso civilizatorio no proviene, según Mandeville, ni del poder de la razón ni de la recompensa ultraterrena que ofrecen las religiones. Dicho impulso proviene del orgullo, del lujo y de las demás pasiones constitutivas de la naturaleza humana, una vez que se produce la transformación de esos impulsos y pasiones naturales en ventajas para la sociedad políticamente organizada. De aquí se extrae como corolario que la tarea civilizatoria o que la verdadera tarea política ilustrada consiste en lograr una hábil administración de las pasiones (lujo, orgullo, ostentación, deseo de sobresalir...) que haga posible un espíritu cívico público que, una vez introducido en las conciencias individuales, conseguirá un cuerpo social y político equilibrado y estable. Mediante este hábil manejo o hábil administración de los impulsos naturales nacerán las ventajas positivas armoniosamente distribuidas. Esta tarea se confía a un largo proceso civilizatorio. En esa tarea el Estado se hace imprescindible y ha de ejercer su vigilancia y su intervencionismo. La acción política ya no buscará moralizar a la sociedad para alcanzar la bondad, "sino persuadirla acerca de la conveniencia de observar el espíritu público como única forma de realización de sus intereses, a través de un modo de vida honorable basado en el reconocimiento intersubjetivo dentro del mercado". ${ }^{132}$ Un ethos virtuoso menos exigente que el de la virtud entendida como abnegación es más efectivo para ese proceso civilizatorio que propiciará un modelo de sociabilidad acorde con una sociedad burguesa y liberal a la que aspiraba Mandeville.

Mandeville pretendía legitimar el nuevo orden social y económico de la Inglaterra de su tiempo, que era

\footnotetext{
${ }^{131}$ HAYEK, F., "La tendencia del pensamiento económico. Ensayos sobre economistas", en Dr. Mandeville, vol. III, Unión Editorial, Madrid, 1970

${ }^{132}$ RÍOS ESPINOSA, Ma C., "Bernard Mandeville: la ética del mercado y la desigualdad social como base del mercado y la desigualdad social como base del progreso moderno", En-claves del pensamiento, vol. 1, no 1, 2007, p. 4. [pp. totales: 1-13.]
} 
incompatible con la noción ya decadente de una virtud rigorista que contradecía las categorías burguesas de una sociedad comercial y abierta a nuevas formas de propiedad. ${ }^{133}$ También se oponía radicalmente Mandeville a la idea -sustentada por Shaftesbuy y por Hutcheson- de que existen en todos los seres humanos cualidades amables y benevolentes inherentes a su naturaleza, llamadas a proporcionar un orden social y político estable.

El aparente rigorismo del concepto de virtud perceptibles en la Fábula de las abejas no es más que un recurso satírico para hacer ver a los seguidores del ascetismo moral y a los racionalistas de su época "la imposibilidad del sujeto de trascender su naturaleza pasional a través de la abnegación. El ethos de la honorabilidad libera al ser humano de la frustración ante la imposibilidad de ser virtuoso". ${ }^{134}$

Es necesario formular algunos aspectos críticos a la ética propugnada por Mandeville. Una de la razones de esta crítica surge del indiferentismo que propugna el autor de la Fábula de las abejas, dado que no se busca la felicidad ni el amor al prójimo, sino que estos estados de moralidad son un mero accidente un mero resultado azaroso de la búsqueda del interés egoísta. Además, las relaciones intersubjetivas se fundan en el utilitarismo social y político. Las relaciones sociales tienen un carácter exclusivamente instrumental que es la búsqueda del interés económico, presuponiéndose un automatismo o funcionalidad del mercado. Esta idealización del mercado, fuera del cual no hay alternativa, conduce a los registros ideológicos del neoliberalismo económico. La esencia humana de la sociedad se cifra en el mercado y el sujeto se convierte en víctima del espíritu del mercado que se conduce de manera espontánea, sin que sea preciso un esfuerzo deliberativo.

La ética de mercado de Mandeville es, por otra parte, contraria a la idea del progreso porque promueve la ignorancia del trabajador y la desigualdad de clases, bajo el presupuesto de que la ignorancia desalienta las ambiciones de los pobres y los hace conformistas, siendo, de este modo, sus necesidades más fácilmente satisfechas. Estas ideas antiprogresistas las expresa Mandeville en su Ensayo sobre la caridad. ${ }^{135}$ En una nación libe, dice Mandeville, en la que no se permite la esclavitud "la riqueza más segura consiste en una multitud de pobres laboriosos; porque además de ser estos el infalible vivero del ejército y de la marina, sin ellos no podrían existir los placeres (...) Para hacer feliz a la sociedad y tener contestas a las gentes, aun en las circunstancias más humildes, es indispensable que el mayor número de ellas sean, al tiempo que pobres, totalmente ignorantes". ${ }^{136}$ La idea del trabajo, según Mandeville, se basa en la pobreza y en la ignorancia, y se enfrentaba, por eso, a las escuelas de Caridad donde se educa a los hijos pobres. Si tienen educación desearán mucho más, aumentarán sus ambiciones

\footnotetext{
${ }^{133}$ El nuevo criterio de interés que se experimenta en la modernidad pasa de ser considerado un vicio a incorporarse al nuevo criterio de racionalidad que consistirá en el cálculo, la moderación y la predictibilidad de la conducta humana. Cfr. HIRSCHMAN, A., The Passions and the Interest: Political Argument for Capitalism Before its Triumph, Princeton, 1977.

${ }^{134}$ RÍOS ESPINOSA, Ma C., "Bernard Mandeville: la ética del mercado y la desigualdad social como base del mercado y la desigualdad social como base del progreso moderno", op. cit.p. 6.

${ }^{135}$ MANDEVILLE, B., Ensayo sobre la caridad y las Escuelas de Caridad, en MANDEVILLE, B., La fábula de las abejas, op. cit., pp. 165-215.

${ }^{136}$ Ibid., p. 190.
} 
y se harán inadaptados. La pobreza y la ignorancia son, por ello, de gran utilidad. Si los salarios son altos los trabajadores se darán al vicio y a la holgazanería. Por el contrario, cuanto más bajos sean los salarios más trabajarán. De este modo se impide también el vicio y la corrupción de las clases pobres. Se puede observar, en definitiva, tras la lectura de este ensayo sobre la caridad que Mandeville adopta una posición reaccionaria, al ponerse a favor de utilidad de pobreza y de la ignorancia.

Según Mandeville, la ignorancia mantiene a lo pobres en un estado de inocencia y de bondad natural, lo que contradice la tesis de la fábula de as abejas en donde se oponía a una idea de la bondad natural en el hombre. Resulta, ahora -a la luz, sobre todo del Ensayo sobre la caridad y de las Observaciones (la "Y" en especial) ${ }^{137}$ que los beneficios públicos es sólo para las clases dominantes y más ricas, siendo los vicios también de las clases pudientes. A la clase trabajadora le recomienda deberes de subordinación e inclinaciones naturales en favor de los explotadores. La clase baja debe ser la más extensa por ser la multitud de los trabajadores pobres la base que todo lo soporta.

Dada la actualidad del pensamiento de Mandeville en la ideología que impregna al liberalismo económico, ${ }^{138}$ es preciso destacar que esa idea de la armonización de intereses por el automatismo del mercado conduce a una utopía imposible. La génesis de una racionalidad dejada al automatismo y espontaneidad, auspiciada por Mandeville, no puede juzgarse como un racionalidad libre y armónica cuando esa racionalidad instrumental genera probreza, exclusión y ausencia de bienes culturales, a cambio de una acumulación de riqueza para los poderes económicos o clase dominantes. Bajo esta posición subyace el presupuesto mandevilliano de que existe el paradigma antropológica natural del hombre dinámico, emprendedor y activo que encarna la tarea civilizatoria del espíritu moderno

Difícilmente puede llamarse "moderno" y "progresista" a un proyecto civilizatorio donde la desigualdad social sea percibida como inevitable para la acumulación de riqueza. No puede, por eso, seguir creyéndose en la "utilidad de la pobreza" que acabó propiciando Mandeville, distanciándose de los postulados irónico-críticos de su Fábula de las abejas.

\footnotetext{
${ }^{137}$ MANDEVILLE, B., "Observaciones", en MANDEVILLE, B., La fábula de las abejas, op. cit., pp. 33-164. En especial la "Y" ("Querer gozar de los beneficios del mundo"), 161-164.

${ }^{138}$ Mandeville ha ejercido su influencia en "en la teoría de la evolución de la civilización de Adam Ferguson, en la idea de espontaneidad del orden del mercado y la mano invisible de Adam Smith, en la teoría poblacional de Malthus, y en la Escuela Austríaca de economía cuyos máximos representantes son Friedrick Hayek y Von Mises" (RÍOS ESPINOSA, Ma C., "Bernard Mandeville: la ética del mercado y la desigualdad social como base del mercado y la desigualdad social como base del progreso moderno", op. cit.p. 9).
} 


\title{
BERNARD MANDEVILLE AND THE PARADOXES OF A SATIRICAL FABULIST
}

\begin{abstract}
The annoying mirror of the fable of the bees has attracted the attention of eminent thinkers and Bernard Mandeville, particularly known as the author of that fable, acquired a well deserved reputation in the culture of the European Enlightenment. The importance of Mandeville's thought at the present time seems to be unquestionable because it is possible to discover in his works a kind of reasoning that legitimizes the appropriate free market to an open commercial and flourishing society, in which the following paradox emerges: self-interest and private vices make public benefit spontaneously. Mandeville defended, as an attribute of his model of society, luxury, greed and selfishness in any possible manifestation, but he did so adopting an ascetic concept of virtue as a satirical instrument. With this ironical resort he sought to unmask the hypocritical mortality of his time, since going deeply into that idea of virtue some manifestation of egoism can be found. Mandeville was convinced that the true urge for action arises from passions sheltering in human nature.
\end{abstract}

Keywords: fable of the bees, private vices, public benefit, ascetic virtue, open commercial society, satirical fabulist, skilful politicians, calm virtues, selfish passions.

\section{BIBLIOGRAFÍA}

CARRIVE, P., Bernard Mandeville. Passions, Vices, Virtues, París, Libraire Philosophique, 1980, pp. 10 y ss.

DEKKER, R., "Private vices, Public Virtues Revised: The Dutch Background of Bernard Mandeville", History of European Ideas, vol. 4, 1992, pp. 482 y ss.

DESCARTES, R, Meditationes de prima philosophia, objectiones quintae, II, 7. Mandeville cita a Gasssendi en el "Prefacio" en La fábula de las abejas II parte, ibid., p. 356.

GOldSMiTH, M. M., Private Vices Public Benefits: Bernard Mandeville's Social and Political Thought, (Revised Edition), Christchurch, New Zealand, Cybereditions Corporation, 2001. Ubicación en la red: http://site.ebray.com/lib/univgranada/Doc?id=5005520\&ppg=1

HOLBACH, Sistema de la naturaleza humana, trad. De Nerida Bacín y otros, Editorial Laetoli, Pamplona, 2008.

KAYE, F.B., “Introducción”, en MANDEVILLE, B., La fábula de las abejas o los vicios privados hacen la prosperidad pública. Traducción de Ferrater Mora

PASCAL, LA ROCHEFOUCAULD, LA BRUYÈRE, VAUVENARGES, CHAMPORT, JOUBERT, Moralistas franceses. Máximas, pensamientos y caracteres, introducción de Alicia Illera, ed. de José Antonio Millán Alba, trad. de Salustiano Masó y José Antonio Millán Alba, Biblioteca de Literatura Universal, Córdoba, Almuzarra, 2008.

RÍOS ESPINOSA, Ma C., Fundamentación ética del mercantilismo. Bernard Mandeville: la paradoja del vicio en la sociedad, Publicackiones Cruz O., Máxico, 2002, p. 43.

SCOTT, Kyle, "Mandeville's Paradox as Satire: The Moral Consequences of Being a Good Citizen in a Commercial Society", Politics \& Policy, nº 2, vol. 37, Abril, 2009, pp. 372-376. 
Trabalho enviado em 26 de dezembro de 2016. Aceito em 27 de fevereiro de 2017. 